\title{
Cities and the Governance of Transport Interfaces: Ethiopia's New Rail Systems
}

\begin{abstract}
This paper investigates the governance of transport infrastructure interfaces. These are connection or touching points that bring together different city systems, technical characteristics and governance regimes. The empirical evidence comes from Ethiopia's new rail systems and is based on experiences in two cities, the capital Addis Ababa and the second largest city Dire Dawa. The techno-spatial and organisational boundaries that define infrastructure interfaces are under-researched across disciplines. Yet it is at these hotspots of urban governance where many critical questions for cities arise: who governs, what to prioritise, how to coordinate? Based on a multiple case study approach, this paper combines socio-spatial analysis with institutional analysis of infrastructure governance. The findings include the identification of highly centralised and hierarchical governance and coordination dynamics, as well as the critical role of a new bureaucracy (the Ethiopian Railway Corporation) structured around core railway engineering competence rather than urban transport and development expertise. More generally, it is a techno-political alliance in Ethiopia which shapes urban development and the rollout of infrastructure at an unprecedented speed and scale.
\end{abstract}

Keywords: integration, infrastructure coordination; interchanges; railways; Sub-Saharan Africa; urbanisation

\section{Introduction}

A vast body of research has documented the shortcomings of top-down transport infrastructure development in cities (Goodwin et al., 1991; Banister, 2005; Cervero et al., 2017). Above all, this includes unequal access, local accessibility traded-off against metropolitan accessibility, place functions of streets replaced by movement functions, reduced road safety, excessive congestion and travel times, and energy intense and polluting urban mobility (Rode et al., 2017). This paper argues that these problems are often the result of failed systems integration and that many of those can be detected, analysed and managed in the context of transport infrastructure interfaces. We define infrastructure interfaces as the physical connection or touching points where different infrastructure systems or sub-systems meet or interact. ${ }^{1}$ Often the most vulnerable components of these systems, interfaces are critical determinants of their overall performance and the makers or breakers of effective transport.

The inherent complexity of infrastructure interfaces typically involves considerable levels of governance hybridity (Beall et al., 2019). Therefore, in this paper, we regard transport infrastructure interfaces as 'hotspots of urban governance' that can embody much wider multilevel governance challenges, as well as the politicisation of infrastructure systems. With

\footnotetext{
${ }^{1}$ In this paper, 'connections' or 'touching points' refer to the different physical components of the infrastructure interface (e.g. the material part of the systems or subsystems). The 'interactions' refer to the technical and nontechnical activities prompted, enabled, mediated or impacted by the physical components (e.g. the use, operation, management and governance of exchanges occurring at the interface).
} 
multiple governmental and non-governmental actors, processes at different levels of formalisation, and public and private ownership, infrastructure interfaces are points of conflict and friction with considerable coordination challenges. Failures at these locations quickly lead to cascading effects across city systems. Yet, understanding the interactions between infrastructure systems and sub-systems alongside governance processes tends to be neglected in urban research and practice.

This paper investigates infrastructure interfaces in two Ethiopian cities, which are part of the country's new rail systems. It inquires how these interfaces are shaped, challenged and coordinated by administrative and political actors. Drawing on empirical evidence, it analyses the challenges and institutional responses that emerge around highly interconnected and complex urban systems. The backdrop of this paper is the contested relationship between wider development goals and large-scale infrastructure roll out (Cirolia and Rode, 2019). While, long-term urban growth and poverty elimination involves improved transport for the movement of people and goods, related infrastructure improvements often compromise other urban development objectives (Hickman et al., 2015). Above all, they frequently fail to facilitate affordable micro and macro level accessibility in cities (Macário, 2014) - the primary urban consumption good (Duranton and Guerra, 2016).

Ethiopia's bold commitment to new railway infrastructure recognises a range of key advantages and urban opportunities for better accessibility (Rode, 2018a; Terrefe, 2018). But the complexity of building and operating railways can be a major obstacle for embracing them as part of urban development strategies. As a closed and highly integrated system, rail transport is unique in its demand for joined-up institutions and governance arrangements. The specificities of railways also include its rigid infrastructure, the need for an operator, complicated interoperability and a system performance that is as functional as its weakest section across the entire line. In addition, railways depend on complementary transport services for 'last mile' connectivity as well as associated electricity supply, communication and signalling systems. Thus, institutional arrangements that are not capable of recognising and managing the interconnectedness of railways and other city systems risk to severely comprise the opportunities (high capacities, safety, reliability and major environmental benefits).

Ethiopia is a particularly instructive case for studying urban infrastructure governance and how new rail transport systems intersect with urban development. While urban dwellers only make up $20 \%$ of its total population - with the remaining 80 million people still living in rural areas - the country has one of the fastest urbanisation rates in the world (African Development Bank, 2016). In response to these growth challenges, Ethiopia has had the highest rate of infrastructure expenditure on the African continent (World Bank, 2016). More specifically, Ethiopia has established itself as a regional leader in sustainable urban development (New Climate Economy, 2015).

Major state-led investments in infrastructure set out in the country's Growth and Transformation Plan (GTP) have resulted in close to double digit growth rates for the last decade (Government of Ethiopia 2010). Addis Ababa, in particular, has received a lot of attention for the rollout of sub-Saharan Africa's first urban Light Rail Transit (LRT), while the Addis-Djibouti Railway (ADR) has provided a new outlet for the world's largest landlocked country. The sheer scale and speed of Ethiopia's infrastructure developments not only require major financial and technical resources, mostly provided by China, but also sophisticated and politically sensitive governance arrangements that enable coordination among multiple stakeholders. A recent analysis estimated that "damages and wastages of resources encountered in Addis Ababa due to lack of integration and cooperation are believed to have reached a minimum of three billion Birr in the last decade" (EiABC, 2016, p.150), the equivalent of USD 
105 million. With major transport infrastructure projects still in the pipeline, the Ethiopian case lends itself to an analysis of governance dynamics, coordination challenges and inherent politics of transport interfaces.

Through a multiple case-study approach and employing the concept of infrastructure interfaces as the analytical framework, this paper aims to answer the following overarching research questions: 'How are Ethiopia's new rail infrastructure interfaces governed in two key cities? What are the related institutional challenges, coordination efforts and effects on urban development?' As part of this investigation, we are not exploring the initial decisions that led to the selection of these infrastructures. Rather, we analyse how - following these decisions the projects were implemented and administered alongside broader urban development efforts.

The remainder of this paper is organised as follows. The second section reviews selected literature on urban infrastructure governance and introduces the concept of infrastructure interfaces, emphasising the aspects that are most relevant for transport and its integration with other infrastructure and city systems. The third section briefly describes the research context, framework and methodology. While the fourth section illustrates and compares the key features of the two case-studies, section five analyses the empirical evidence and outlines the findings. The sixth section concludes the paper.

\section{Governing interdependencies: the case of urban transport infrastructure}

As part of new forms of urban governance, it has been argued that rather than seeking 'optimal' solutions, governments ought to find 'good enough' solutions and endorse suitable 'enabling environments' to manage complexity (da Cruz et al., 2019). Many governance challenges have such a degree of interconnectedness that interventions aiming to address them often tend to make the problems worse (Rittel and Webber, 1973). Global experiences with governing urban transport have repeatedly illustrated that infrastructure development fails to establish better and more efficient accessibility in cities (Rode et al., 2019).

Cities are an exemplary case of 'small world' advantages (Batty, 2010) where high densities enable accessibility to people, goods and ideas. Nested within their confined territories, many overlapping, interdependent and semi-autonomous systems support cities in their accessibility function. There have been several strands of literature dealing with the system-of-systems character of cities, which recognise the "multiple, heterogeneous, distributed, occasionally independent operating systems embedded in networks at multiple levels, which evolve over time" (DeLaurentis, 2007, p365).

Urban infrastructure systems and sub-systems have an interconnected and co-constitutive character (Graham and Marvin, 2001; Derrible, 2017). Sanitation systems, which connect with buildings and their internal functions, power supply networks that activate transport systems, and transport infrastructure which enables waste management are examples of such functional interrelatedness. In some cases, this interrelatedness is merely complementary where infrastructure services are co-produced. In many instances, however, these relationships go well beyond synergies and are characterised by fundamental dependencies and interoperability requirements that, if compromised, risk basic functionality.

By contrast, conflicting interrelatedness may require trade-offs and negotiation between subsystems (Heeres et al., 2016). Prominent examples are conflicting land uses between linear infrastructures - with their right-of-way requirements - and sites of stationary functions such as buildings and other facilities. Many urban problems are directly linked to the disregard of conflicting interrelatedness. Experiences with road infrastructure development are particularly illustrative of this. When these are planned and deployed in isolation from broader urban 
development concerns, their disruptive nature can destabilise other critical city systems and result in cost and time overruns, as well as poor quality and legitimacy concerns (Heeres et al., 2016; Derrible, 2017).

These technological assemblages are not the exclusive reserve of cities and urban contexts. In fact, the basic premise of systems engineering (Jamshidi, 2008) is centrally attached to better addressing such technological interdependencies. However, it is in urban spaces where technological interdependencies are super-scaled due to the multiplier effects of higher densities and the interaction of both technical and non-technical systems across and within social, economic and ecological domains at significantly higher levels. This observation has recently stimulated considerable interest in the idea of an urban nexus of systems (GIZ and ICLEI, 2014; Walker et al., 2014; Daher and Mohtar, 2015; Lu and Chen, 2016; Artioli et al., 2017). The urban nexus approach articulates the importance of systems integration and integrated development alongside new ideas on how innovative forms of governance may enable these (Holland, 2000; GIZ and ICLEI, 2014; Rode, 2018b).

The two sub-sections below take account of questions linked to infrastructure interfaces and integrated governance which frame this paper.

\subsection{Transport infrastructure interfaces}

Infrastructure interfaces are the physical connection or touching points between different components of infrastructure systems. These components are usually discrete system elements that share the same material, functional or structural characteristics (e.g. the track) and tend to be subjected to the same type of control, ownership and oversight (e.g. transport operator, city government, utility company). In turn, infrastructure interfaces exist, for example, at the point where different technologies (e.g. analogue/digital), flows (e.g. higher/lower speeds), scales (national/metropolitan/local), ages (new/old) or design lives (long/short) of system components interact. These interfaces may function as access points to the overall system or as parts of its internal workings. In this paper, we also accept that infrastructure interfaces can be identified at different levels of granularity (see Table 1) and we apply the concept for an entire transport interchange which may connect regional rail, minibus and pedestrian infrastructure as well as lower level interaction points between its sub-elements such as tracks, platforms and bridges. Besides these 'active' interfaces - which connect the constituent parts of an infrastructure system - there are 'passive' interfaces where certain unconnected sub-systems coexist and 'touch' each other without being 'in dialogue' (and sometimes even coexisting 'in conflict'). Railway crossings or highway underpasses are typical examples of the latter. Furthermore, these interfaces not only exist within but also across different infrastructure sectors.

Despite the importance of these interfaces and the related technical and non-technical (sub)systems' interactions - and perhaps because disciplinary expertise tends to also change or coexist at these junctures - research on the governance of infrastructure interfaces is sparse. In fact, a quantitative review of directly related terminology of all socio-scientific research indexed in the Web of Science and Scopus only returned 19 unique references alluding to the governance of infrastructure interfaces. ${ }^{2}$ The majority (11 references) focus on the Global South and look into transport (nine references) or water and sanitation (three) systems. Evidently, this 'parameterised' review is limited in capturing specialised literature on 'urban networks' and 'network urbanism' and its exploration of the role of interfaces as techno-spatial

\footnotetext{
2 The search terms 'infrastructure interfac*' and 'infrastructure connect*' where combined with the search terms 'regulat*', 'manag*', and 'govern*' to carry out the review.
} 
and organisational connections in transport and other infrastructure sectors (e.g. Dupuy 2008). It also does not include recent literature that tackles these issues using different or sectorspecific terms such as 'interchanges' or 'junctions' (Newlove-Eriksson, 2019). Nonetheless, this brief review shows that adopting the concept of infrastructure interface as a point of departure and analytical device fills a gap in the literature and represents an innovation in the way coordination processes are researched.

Table 1: Examples of intra-sector and inter-sector transport infrastructure interfaces at different scales.

\begin{tabular}{|c|c|c|c|c|}
\hline \multirow{2}{*}{$\begin{array}{l}\text { Geographic } \\
\text { scale }\end{array}$} & \multirow{2}{*}{$\begin{array}{l}\text { Intra-sector interfaces } \\
\text { (within transport) }\end{array}$} & \multicolumn{3}{|c|}{ Inter-sector interfaces (with transport) } \\
\hline & & Water & Electricity & Telecom \\
\hline System-wide & & $\begin{array}{l}\text { Surfaces (permeability) } \\
\text { Pipes and tunnels (right } \\
\text { of way) } \\
\text { Capacity (flooding) } \\
\text { Structure (functionality } \\
\text { and safety) }\end{array}$ & $\begin{array}{l}\text { Overhead wires } \\
\text { (electric propulsion) } \\
\text { Grid connection } \\
\text { (power supply) } \\
\text { Power lines (right of } \\
\text { way) }\end{array}$ & $\begin{array}{l}\text { Communication } \\
\text { cables (system } \\
\text { support) } \\
\text { Connected vehicles } \\
\text { (GPS, coordination) }\end{array}$ \\
\hline National & Airports, ports & $\begin{array}{l}\text { Dams (roads), } \\
\text { aqueducts (e.g. canals) }\end{array}$ & $\begin{array}{l}\text { Power stations (e.g. } \\
\text { transport of fuel) }\end{array}$ & $\begin{array}{l}\text { Data centres (e.g. } \\
\text { security, } \\
\text { redundancy) }\end{array}$ \\
\hline Metropolitan & $\begin{array}{l}\text { National/regional } \\
\text { railways - urban railways, } \\
\text { highways - main roads }\end{array}$ & $\begin{array}{l}\text { Transmission mains } \\
\text { (maintenance) }\end{array}$ & $\begin{array}{l}\text { High voltage power } \\
\text { transmission } \\
\text { (maintenance and } \\
\text { safety) }\end{array}$ & \\
\hline City & $\begin{array}{l}\text { Main roads - streets, train } \\
\text { stations, bus and coach } \\
\text { terminals, bus depots, taxi } \\
\text { depots }\end{array}$ & $\begin{array}{l}\text { Water mains, valves } \\
\text { and pumps } \\
\text { (maintenance), } \\
\text { wastewater treatment } \\
\text { plants (e.g. transport of } \\
\text { materials) }\end{array}$ & $\begin{array}{l}\text { Substations, cables } \\
\text { (maintenance) }\end{array}$ & $\begin{array}{l}\text { Cables } \\
\text { (maintenance) }\end{array}$ \\
\hline Neighbourhood & $\begin{array}{l}\text { LRT stations, LRT rails, } \\
\text { streets - pedestrian } \\
\text { infrastructure, bus stops, } \\
\text { taxi ranks, bicycle docks }\end{array}$ & $\begin{array}{l}\text { Street mains, service / } \\
\text { distribution pipes, } \\
\text { valves, manholes, } \\
\text { gutters, sewers and } \\
\text { septic tanks } \\
\text { (maintenance) }\end{array}$ & $\begin{array}{l}\text { Traffic signs, traffic } \\
\text { lights, street lighting }\end{array}$ & $\begin{array}{l}\text { Traffic signs, traffic } \\
\text { lights }\end{array}$ \\
\hline Site & $\begin{array}{l}\text { Platforms, gates, } \\
\text { stairways, escalators, } \\
\text { elevators, ticket machines }\end{array}$ & $\begin{array}{l}\text { Toilets, water } \\
\text { fountains, drains } \\
\text { (maintenance) }\end{array}$ & Lighting (e.g. safety) & $\begin{array}{l}\text { Live } \\
\text { arrival/departure } \\
\text { information }\end{array}$ \\
\hline
\end{tabular}

Active infrastructure interfaces within the transport sector connect systems or sub-systems operating at different speeds, levels of granularity, loads and volumes. In cities, there is a constant negotiation between connecting nodes and bypassing lower level links (Batty 2010), or between active and passive interfaces. Figure 1 presents a simple taxonomy of transport infrastructure interfaces and an overview of how these are situated within the broader city system. The overarching concern framing this paper is the governance of the wider sphere of transport infrastructure interfaces (see ' $A$ ' in Figure 1), which relates to the wider social systems of urban governance. Of particular interest for our research are three interfaces that are part of the technical transport system. The first are active interfaces ('\#1') enabling the provision of access between system components dedicated to facilitating mobility (streets, railways, etc.) and those characterised by their stationary/place function (buildings, green space, etc.). The second are mobility interfaces (' $\# 2$ ') connecting different modes of travel (e.g. changing from bus to train or from walking to taking a taxi). The third are inter-sector interfaces 
('\#3') that are not part of the core accessibility function while linking transport to other technical city systems and functions (e.g. transport and electricity systems or transport and drainage systems).

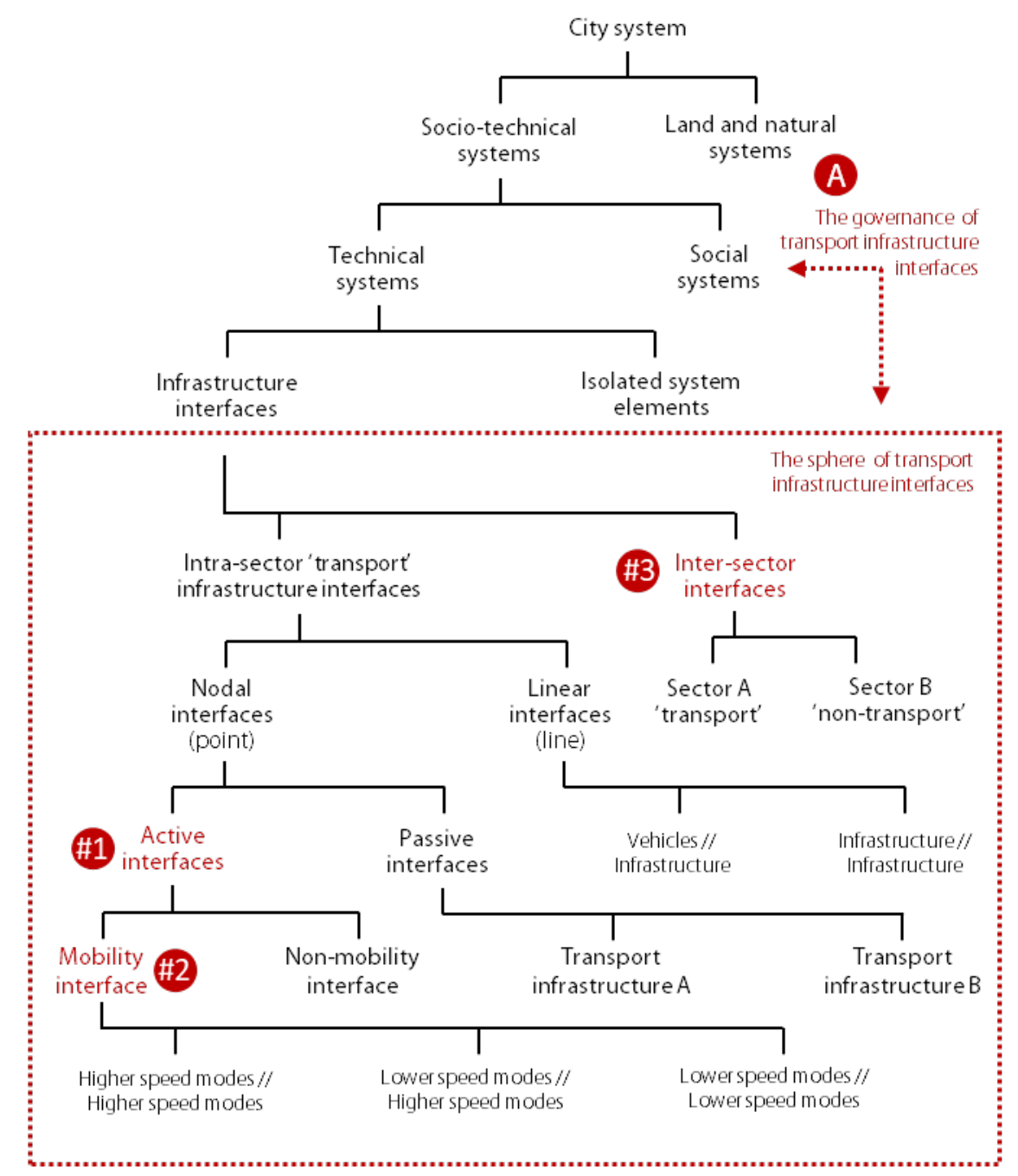

Figure 1. Taxonomy of transport infrastructure interfaces (source: authors). ${ }^{3}$

The interrelatedness of urban infrastructure systems is materialised at the interfaces. For the reasons discussed above, designing, managing and governing these physical connection points should be concerns that cut across disciplines and professional boundaries. In practice, however, this is usually the exclusive domain of engineering and other technical and apolitical disciplines. Consequently, 'optimising' and problem-avoiding approaches often guide the process where, instead of embracing complexity, there is an attempt to avoid or reduce it:

"Wherever possible, remove the interface entirely. Not always possible, of course, so remove unnecessary movement, think across the interface, lubricate the interface and understand the system objectives." (Kessel, 2012, para 13)

A practical example of this in the transport sector is building a rail station far from the city centre where the density of other systems - and the likelihood of further interfaces - is higher. This is similar to the 'build-it-and-they-will-come' approach of engineering which has been

\footnotetext{
3 This diagram identifies the primary hierarchy of interfaces for the case of transport. The differentiation across this hierarchy can be repeated also for the branches not further explored in this illustration.
} 
extensively criticised in the literature (Brooker, 2012; Slater et al., 2016). But even without considering the interactions with social systems (i.e. with people), the interactions between infrastructure systems are quite complex by themselves.

A useful way to identify and spatialize infrastructure interfaces is thus clustering them by geographical scale. Indeed, some interfaces only occur or are relevant at particular scales. Table 1 shows examples of transport infrastructure interfaces (intra-sector) and of interfaces between transport and other infrastructure systems (inter-sector) as they crop up at various scales. At each of these interfaces we can observe and zoom-in on technical issues - such as compatibility and standardisation (e.g. platform heights, coexistence and transition between modes) - and on actual use - such as activities and flows (of people, of things, of capital, formal and informal, legal and illegal). After developing this detailed understanding about the operations, we can start to map out the stakeholders, rules, responsibilities and institutions. We employ this concept of investigating infrastructure interfaces as part of our spatial systems analysis in Section 4.

\subsection{Integrated Governance}

Coordinating technical systems alongside other urban activities leads to the complex patterns of cooperation we can observe in cities (Coward and Salingaros, 2004). Together with increasing demands for addressing crosscutting challenges, this has led to ample interest in integrated urban governance (Richards, 1999; UN Habitat, 2009; Rydin, 2011; UNEP, 2011; Bertolini, 2012; GIZ and ICLEI, 2014; UN, 2016; Rode, 2018b). In a nutshell, integrated governance aims to (Rode, 2018b): take advantage of synergetic effects and improve policy coherence; avoid blind spots, inefficient duplication and redundancy; overcome poor sequencing; enhance social learning; and break organisational lock-in to escape institutional inertia and enable innovation.

Underpinning the relevance of integrated governance for cities is the recognition that a "shared spatial system" (Heeres et al., 2016, p422) demands an integrated approach. For example, economists emphasise that cities are built around 'integrated returns' by profiting from a range of cross-sectoral synergies, economies of scale and lower transport costs - which demands appropriate planning and policy practice (Krugman, 1991; Glaeser, 2008). Calls for strengthening integration are typically related to market and policy failures and, particularly in cities, by the desire to address the negative outcomes of sectoral policies of previous decades (Rode, 2018b).

A particular challenge for integrated urban governance are the implications of dealing with complex systems. For example, it may need to acknowledge the 'requisite variety' (Ashby, 1957; Jessop, 2003) which suggests that any system of control requires "the same variety or diversity as the city itself' (Batty, 2010, p114). Bertolini (2010) lists a number of governance approaches, which directly aim to address complexity ranging from approaches that emphasise adaptive governance (Dietz et al., 2003), strategic choice (Friend and Hickling, 2005) and robust decision making (Lempert et al., 2003). Rather than defining final parameters, these

approaches are more focused on the process. For example, robust decision making identifies actions that are defendable for a larger range of future scenarios (Lempert et al., 2003). A fundamental logic for addressing complexity is to increase the number of planning and governance options, while replacing goal maximisation with process optimisation (de Roo, 2010).

Questions about more integrated designs for urban infrastructure have become particularly pertinent as a result of splintering systems (Graham and Marvin, 2001; Graham, 2009), the 
decentralisation of systems and new requirements for infrastructure resilience (Derrible, 2017), an urgent need for integrating above all transport infrastructure with spatial development (Rode, 2018b) and various ecological concerns (Hajer, 1995; Geerlings and Stead, 2003; Kennedy et al., 2005).

A particularly helpful framework for transport infrastructure integration is the 'line to areaoriented' integration spectrum by Heeres et al (2012). This framework positions six integration approaches on two axis. A horizontal axis with the number of actors involved and a vertical axis for the level of integration ranging from sectoral approaches to internal and then to external integration. While sectoral approaches feature little integration and are essentially divided by impermeable silos, internal integration joins-up interventions within one policy domain such as transport and external integration combines different sectors, for example transport and land use (de Roo, 2003). Heeres et al (2012) list the following integrations approaches for the case of road infrastructure:

1. Traditional, line-oriented: sector-oriented and regulation-oriented planning regime, largely neglecting the physical incorporation of the road within a wider area;

2. Network: new roads are seen as part of the wider transport system, including other roads and transport modes, thus involving different actors from the mobility and transport sector;

3. Routing: minimal recognition of the importance of surroundings (initial step towards areaoriented planning);

4. Context-sensitive designs: increased attention to the aesthetic aspects of road infrastructure planning (efforts are made to improve the spatial quality of the road and its surroundings);

5. Area-oriented planning: integrating transport planning and objectives with complementary interests and further developments in a specific area;

6. Area-development processes: collaborative planning process that takes into account all interests in an area (total design) and where new road infrastructure is determined by the development of other functions.

For operationalising integrated governance or the aforementioned integration approaches in planning, Rode (2018b) proposes a framework of four main groups of integration mechanisms (Figure 2): those related to governance structures, those that focus primarily on processes of planning and policymaking, a range of more specific integration instruments and, underlying enabling conditions. Such mechanisms can target integration at strategic or operational levels (Heeres et al., 2016). After mapping the functional interrelatedness at our interface case studies, we employ these two frameworks in the empirical part of this paper to analyse their institutional arrangements and coordination requirements. 


\section{static, formal, visible}
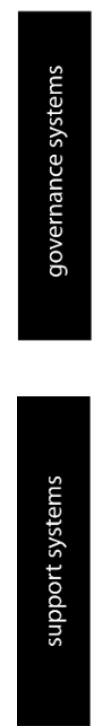

\section{(1) STRUCTURES}

- system boundaries as

administrative boundaries

- central node single

leadership

- networks of trust and

mutual interest

(3) INSTRUMENTS

- information and

communication technology

- strategic visions and

integrated plans

- multi-criteria assessments

and resource distribution dynamic, variable, invisible

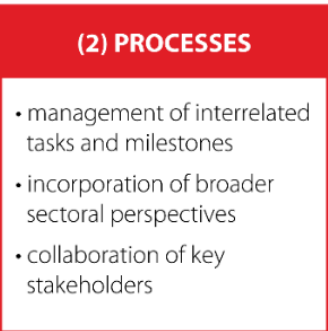

(4) ENABLING

- capacities of individuals, groups and civil society

- leadership and quality of senior officials

- knowledge, experience and collaborative culture

Figure 2. Four principal groups of integration mechanisms (source: Rode, 2018b).

\section{Research framework and methodology}

This paper inquires how new rail transport projects in Ethiopia are being governed at their key interfaces with other city systems. Looking through the lens of infrastructure interfaces makes coordination and integration shortcomings visible and more obvious to observers and researchers beyond those coming from technical disciplines. This research strategy also allows to ground more abstract and theoretical notions of integrated governance in specific material realities which assist in breaking down the complexity of the subject. The analysis of specific and localised requirements allows us to link back to higher levels of coordination, studying the political through the material. Thus, examining the governance of infrastructure interfaces serves as an inductive and multidisciplinary-by-design approach to understanding specific moments of coordination processes.

Conducting our research in Ethiopia required us to productively engage with the political context in which the country's rapid infrastructure roll-out took place. For that, the interface framework is particularly helpful as it allows approaching a political science interest in governance coordination via the substantive concern of joining-up technical systems - an apolitical entry point to the focus of this paper.

Our empirical research employs a multiple case study method (Yin, 2013) which "examines multiple situations within an overall framework" (Agranoff and Radin, 1991, p.204) and focuses on Ethiopia's two 'crucial and revelatory' rail projects, the Addis Ababa LRT and the ADR, and their respective interfaces in Addis Ababa and Dire Dawa. Although substantially different in size, the two selected cities are the only 'chartered' cities in Ethiopia with relatively high levels of autonomy and, as cities 'under construction', they are central cases for contemporary research on urban development in Sub-Saharan Africa. Addis Ababa is the country's dominating urban hub and Dire Dawa the second most dynamic city with far reaching plans for new industrial development induced by the railway.

The two case-study cities were mainly selected as information-oriented case studies (Flyvbjerg, 2006) and as 'critical cases' (i.e. cities that are of particular relevance for a better understanding of the governance of new rail infrastructure interfaces), while also taking into consideration 
'extreme case' selection (i.e. larger cities in Ethiopia which are most impacted by new rail infrastructure and are expected to involve interfaces with considerable levels of complexity). Besides these similarities, there are considerable differences between them (Table 2) that support a broader generalisation of research findings. We consider the two cases as functional equivalents which share key characteristics allowing for comparison while their differences enable analytic generalisation.

Table 2. Relevant similarities and differences between Leghar and Dire Dawa stations for research framework.

\begin{tabular}{|c|c|}
\hline Similarities & Differences \\
\hline - $\quad$ Key rail projects & - $\quad$ Light rail vs heavy rail \\
\hline - $\quad$ Same political motivation & - Urban vs national rail \\
\hline - $\quad$ Same overarching delivery agency & - $\quad$ Passenger vs passenger/freight transport \\
\hline - $\quad$ Chartered host cities & - Inner city vs green field station \\
\hline - Central in Ethiopia's Growth and & - $\quad$ First vs second tier city \\
\hline Transformation Plan & - Capital vs non-capital city \\
\hline - $\quad$ Same financiers & \\
\hline
\end{tabular}

In Addis Ababa, the selection of a specific infrastructure interface, 'the Leghar station', was based on the following criteria: (1) level of infrastructural complexity, (2) embeddedness in representative and broader urban development dynamics, (3) diversity of governance regimes and number of key actors involved, (4) level of politicisation, and (5) access to information and key actors (feasibility). The choice of the infrastructure interface in Dire Dawa, 'the Dire Dawa station', was more straightforward (as it is the city's only station of the new railway line).

Both case studies are primarily 'active' transport infrastructure interfaces which display interdependencies both within the transport system (intra-sector interfaces) as well as with other technical systems (inter-sector interfaces). The data collection and analysis was based on three main elements: first, mapping the physical characteristics of the infrastructure interfaces and relevant socio-economic dynamics; second, interviewing experts and key actors across stakeholder groups; and third, secondary data collection and analysis based on existing infrastructural plans, supportive archival records and documentary information. In addition, a stakeholder workshop on the 5 December 2018 was conducted to receive primary feedback on the analytical approach and initial research findings.

For the spatial analysis of the two interfaces based on the infrastructure interface concept, we applied three different resolution levels for which different types and levels of detail of information was collected. The highest level of resolution (A) was 150 by 150 meters for Leghar and 250 by 250 meters for Dire Dawa - determined by the dimensions of the core interface (platform lengths, station entrances etc.). The medium resolution (B) was 500 by 500 meters for Leghar and 6 by 2 kilometers for Dire Dawa - determined by land holdings directly linked to the related railway and transport operations. The lowest level of resolution (C) was 1 by 1 kilometre for Leghar and 20 by 20 kilometres for Dire Dawa - determined by the immediate catchment area of the provided rail services. These resolution levels were verified and discussed at our stakeholder workshop.

These different resolution levels allowed a scan and systematic categorisation of the different systems as well as their components (nodes) at the infrastructure interface. In doing so, we were able to identify the most relevant technical interactions (ties) between them.

The governance analysis was informed by Rode's (2018b) framework for operationalising integrated governance. Data collection and analysis is based on an iterative approach. We draw 
on Corbin and Strauss' (2014) theoretical sampling applied for qualitative research which interrelates research analysis and data collection. Theoretical sampling has become an established 'step-by-step' method for data collection in qualitative research including expert interviews (Flick, 2014; Littig and Pöchhacker, 2014) where each interview can help in identifying additional interviewees (Bogner et al., 2009).

Given the particular importance of semi-structured expert interviews, our text-based analysis made use of written memos and summaries of particularly important passages from interviews. Similarly, extracts from documentary information and archival records were processed in such a way that either relevant passages of the original texts or summaries were added to the data pool. The computer programme NVivo served as the central tool for analysing the textual data.

A first phase of 'collect and analyse', which included the interrelated data collection and analysis for each of the case studies individually, was followed by a phase of 'compare and conclude', which combined, compared and contrasted the findings of the previous phase in order to establish the desired theoretical generalisations.

The process of identifying experts for this study combined the above-mentioned theoretical sampling of our data sources with 'purposive sampling' (Flick, 2014). Irrespective of our general approach of theoretical sampling, we operated with a general anticipation of the number and roles of interviewees. Of interest were individuals with particular functions within an organisational or institutional situation. The main approach for identifying a first group of experts to be contacted for interviewing relied on three inputs. First, some of the documentary information, above all existing studies, contained information on key organisations, positions and/or individuals of relevance to our research questions. Second, prior expert interviews for other but related research and third, we relied on our own judgement and knowledge regarding the potential of gaining access to relevant information by interviewing individuals who we already knew or were aware of.

The most relevant initial entry point to identify experts among stakeholder groups followed the infrastructure interface concept and a form of 'spatialising' the remits of the various stakeholders involved. Instead of a simple (aspatial) institutional analysis, documenting the various roles and responsibilities, this approach overlays the governance onto the physical world and links particular material components with specific institutional mandates as well as processes. This allowed us to illustrate the complexity of infrastructure systems, the array of specialisms and disciplines involved in place-making, and how infrastructure interfaces relate to institutional interfaces. Higher densities of stakeholders may represent more complex institutional environments - but these environments can also offer more opportunities for innovation and collaboration.

Establishing and constantly updating a list of key stakeholders and organisation and their involvement across various project phases was of considerable importance for the identification of the relevant political leaders, directors and senior officials we interviewed (see the final version in Appendix 2).

The governance-related aspects of our research mainly relied on semi-structured expert/elite interviews (Pfadenhauer, 2009; Littig and Pöchhacker, 2014; Flick, 2014). As part of these interviews, three scales of coordination were discussed separately: system-wide coordination efforts, corridor-related coordination, and coordination efforts linked to the chosen transport interfaces. Ethiopia is considered a "poor information environment" (Ahram and Goode, 2016, p.841) and while the Ethiopian government has in recent months been more transparent, "few ruling parties have surrounded themselves with such a wall of secrecy and opacity" as the Ethiopian People's Revolutionary Democratic Front (EPRDF) (Lefort, 2013, p.461). It is for 
this reason that none of the interviews were recorded and we have decided to maintain the anonymity of these elites. A list of all 46 expert interviewees alongside the standard interview script plus reasoning of questions is included in Appendix 3 (in line with our university and funder's ethical guidelines).

\section{The Two Interfaces: Leghar station (LRT) and Dire Dawa station (ADR)}

Two new railway projects in Ethiopia underpin our research of transport interfaces (see the timeline of Ethiopia's Railway Projects in Appendix 1). The first project is Addis Ababa's 34 km LRT system, which opened in 2015 and cost US\$475 million (Kassahun and Bishu, 2015). China's Export-Import Bank (EXIM) funded 75\%, while the remaining 25\% were covered by the Ethiopian government (Nallet, 2018). The Ethiopian Railway Corporation (ERC) contracted the China Railway Engineering Corporation (CREC) to construct its North-South and East-West lines with 39 newly built stations. The LRT was developed to connect inner city business and transport hubs with rapidly developing commercial centres and new housing developments at the urban periphery.

Although at considerable cost, Addis Ababa's light rail system is generally considered a major improvement to the city's public transport system and a pioneering project in Sub-Saharan Africa with an average monthly passenger volume of 3.1 million people between 2016 and 2018 (Ethiopian Railway Corporation, 2018). At the same time, the system is suffering from various design flaws which have reduced its potential to improve overall accessibility. Commentators have highlighted overall capacity constraints, the lacking integration of different transport modes at the main LRT interchanges and that most stations suffer from constrained and un-safe pedestrian accessibility (Nallet, 2018; Kassahun and Bishu, 2015). Furthermore, in many instances, LRT infrastructure has increased the level of severance between and within urban neighbourhoods and compromised local micro-accessibility, challenging local commercial or site-specific activities by limiting pedestrian and vehicular movements.

The second project is the Addis-Djibouti Railway (ADR), a $759 \mathrm{~km}$ electrified, single-track line costing US\$4.2 billion backed by loans from China's EXIM Bank (Golubski, 2017). Operational since early 2018, the railway descends from Addis Ababa's new Furi Lebu Station at 2,300 metres above sea-level to Adama and then through the Awash Basin and along the Rift Valley to the Gulf of Aden, it serves several other second tier cities such as Bishoftu and Dire Dawa along its 17 major stations (of which only 5 are served at the time of writing for passengers transport). For this project, the ERC contracted two Chinese contractors, CREC and China Civil Engineering and Construction Corporation (CCECC) to construct the railway starting at both terminals inwards. The route, designed as Ethiopia's main transport corridor includes industrial parks and dry ports and connects the landlocked country with Djibouti Port, which has handled more than $95 \%$ of its international trade in the last decade (Terrefe, 2018).

In the context of Dire Dawa's new connection to the ADR line, major new economic opportunities have been established as part of a potentially more sustainable, rail-based transport corridor. But these opportunities pose challenges and questions about provision, interconnectivity and use of space as part of industrialisation-led urbanisation. The project's focus on relevant infrastructure interfaces provides an approach to exploring the extent to which developmental concerns with productivity, urbanisation and industrialisation positively or negatively interact with issues that are of great concern for city dwellers: service provision, spatial justice and local accessibility. 
The following sub-sections build on the infrastructure interface concept introduced earlier and include the above mentioned 'spatialisation' of involved stakeholders.

\subsection{Addis Ababa Leghar LRT station}

The Leghar station is located at the geographic and symbolic centre of Addis Ababa. Located in the Kirkos sub-city district, with Mexico roundabout to the west, Stadium to the east, Churchill Road to the north and the historic Ethio-Djibouti Railway Station to the south, the Leghar LRT station sits at a central node for transport in Addis Ababa. The station is one of five along the entire LRT system that serves both East-West and North-South lines, selling on average 2000 tickets per day according to a Ticket Seller's accounting documents (2019). The Leghar LRT station is elevated above the street level to enable seamless flow of traffic from all directions, unlike the ground-level stations in other parts of the city that have increased congestion and constrained accessibility for vehicles and pedestrians. The planning and construction phase of the Leghar LRT station brought together numerous inter-sector and intrasector stakeholders, ranging from federal government agencies to city-wide stakeholders and utility companies to station-specific actors (see Figure 3 ). The material connection points at this interface also were frictious connection points between various technical, political, international and local actors.

The wider Leghar Area analysed at the lower resolution level is also subject to new and significant developments. The Structure Plan of the City (2017-2027) outlines plans for a major transport hub that houses LRT, Bus-Rapid Transit (BRT), bus, taxi and inter-city railway stations in an effort to create multi-modal transport centres (AACPPO, 2017). At the same time, 36 hectares to the south of the Leghar station have been allocated for a real-estate complex "LaGare" to be built by Dubai-based developer Eagle Hills. The speculative real estate investments in the centre of Ethiopia's capital are also visible with numerous high-rises soon to surround the Leghar station, including the Headquarters of Wegagen Bank, Bank of Abyssinia, Ethiopian Insurance Cooperation, the Amhara Development Association and the Ethiopian Shipping Lines \& Logistics Services.

As shown in Figure 3, the Leghar interface brings together many stakeholders where the Addis Ababa City Administration and the ERC are the foremost actors with jurisdiction over many infrastructural elements. This suggests that, to a large extent, the "success" of the interface relies on the level of coordination between these two key stakeholders. However, the governance of this interface is complex even at the level of each of these singular elements. 

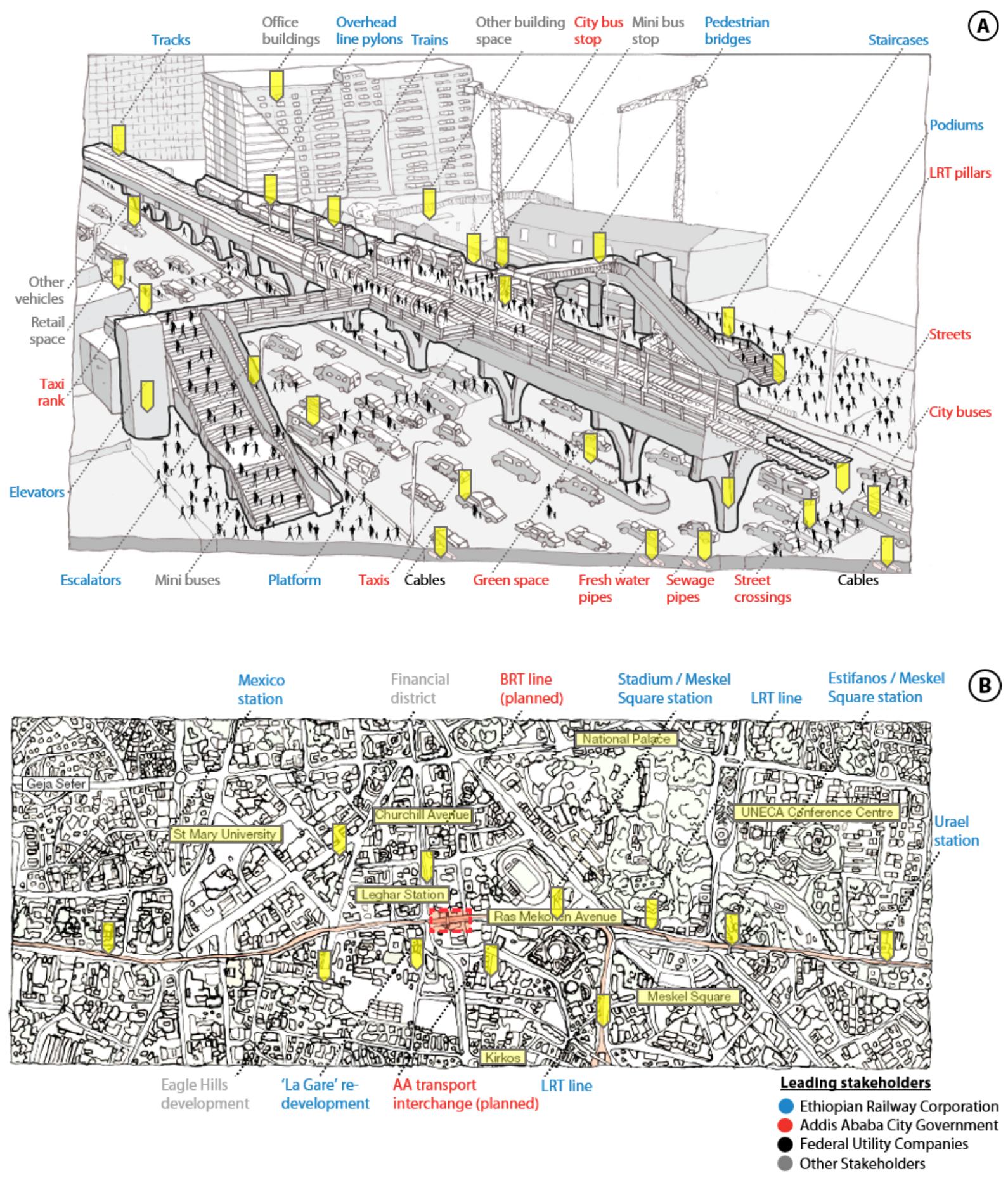

Figure 3. Leghar interface and stakeholders (A) high resolution (approximately 150 by 150 meters), (B) low resolution (approximately 2.5 by 1 kilometres) (source: authors).

For most of the elements where the ERC is leading many other stakeholders also exert (or exerted, see Appendix 2) a certain degree of influence. ${ }^{4}$ The positioning of one of the pillars of

4 The Prime Minister's Office (the ties with the ERC were particular strong during the planning and implementation phases), the Ministry of Transport (MoT), the Ministry of Finance and Economic Development (MoFED), Lyon Urban Town Planning (consulting with planners from Addis Ababa's sister city was key in the initial stage of the project), China Railways Eryuan Engineering Group, CREC, and China Exim-Bank. Similarly, the oversight of Addis Ababa City Administration is deployed through various departments, offices, city agencies and commissions, and municipal companies and authorities (which, in general, exhibit very low degrees of collaboration and communication amongst them), namely: the Addis Ababa Master Planning Office (later 
the elevated railway in the middle of one of the busiest and previously most emblematic intersections of the city (to reduce the costs of an otherwise longer span - right end side of Figure 3A) illustrates the limited ability of the Addis Ababa City Administration to make a stronger case to the ERC about critical trade-offs (e.g. road congestion, view corridors and urban design qualities).

The other leading actors identified in Figure 3A include federal utility companies such as Ethiotelecom and Ethiopian Electric Power. The governance complexity of the LRT station interface is also compounded by the presence of private building and land leasers as well as more informal activities such by the minibus operations, the settlements being displaced by the "La Gare" redevelopment project (a federally-sponsored initiative), and the retail activities that emerge organically at these hotspots.

\subsection{Dire Dawa ADR station}

Dire Dawa is Ethiopia's second largest city located in the east of the country. Kezira, the historic and geographic centre of the city, was built as a settlement surrounding the old Frenchbuilt railway station in 1902. The historic importance and continued presence of the old railway in the psyche of Dire Dawa residents is central to their perception and acceptance of the new railway (Terrefe, 2018). The new standard-gauge railway, by contrast, is located approximately ten kilometres outside of the city centre next to the new Dire Dawa Industrial Park and Dry Port (see Figure 4). While residents of the city centre shared sentiments of disconnection and frustrations about the government's "tunnel vision", officials at the ERC were clear about the expanding nature of the city and its industrial capacity (Terrefe, 2018). According to a senior advisor at the Dire Dawa Mayor's Office (2018), 4,200 hectares of land between Melka Jebdu (the location of the new railway station) and Hurso (a smaller town in the Somali region to the east of Dire Dawa) are allocated to be part Dire Dawa's wider Industrial Zone. The Dire Dawa station is physically located between two Kebeles (the smallest administrative unit in Ethiopia), Melka Jebdu and Goladen, which in turn are located in the Dire Dawa metropolitan area and the Somali Regional State respectively. This interface was constructed at the border of municipal and regional boundaries, which had major implications for the processes of land acquisition, compensation and relocation of local communities during the planning and construction phase.

While the railway is integral to wider industrialisation and urbanization dynamics, the ERC centralised most activities during the planning, construction and operation phases. This is best exemplified by the fact that an exclusively dedicated single fibre-optic cable was laid alongside the railway to provide reliable internet and a single ticketing system to all stations. Whereas the ERC depended on other stakeholders such as Ethiotelecom, Ethiopian Electric Power and Addis Ababa Water and Sewage Authority for the Addis Ababa LRT stations, the ERC was not dependent on the Dire Dawa city administration for the provision of internet, electricity and even water. The station is also loosely connected to local transport systems, with minibuses sparsely frequenting the station during arrival times. Figure 4 also makes clear that the scale of analysis for the Dire Dawa interfaces is larger than for Leghar's, given the station's size, its peri-urban location and industrialising function.

replaced by the Addis Ababa Plan Commission), the Land Development and Management Bureau, the Addis Ababa City Road Authority (AACRA), the Addis Ababa Water \& Sanitation Authority, the Road and Transport Bureau, and the Police Commission. 

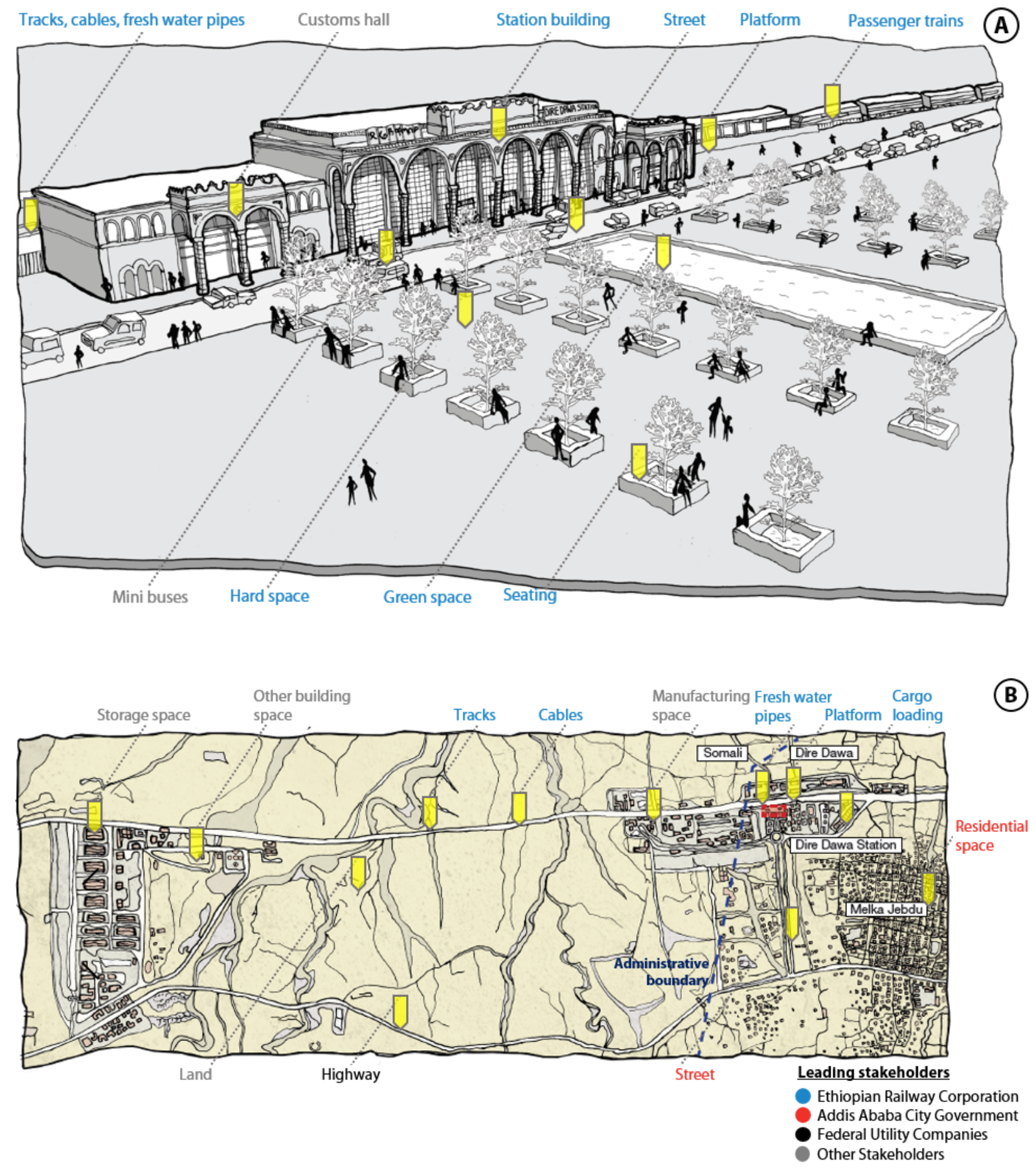

Figure 4. Dire Dawa interface and stakeholders (A) high resolution (approximately 250 by 250 meters), (B) medium resolution (approximately 6 by 2 kilometres) (source: authors).

The Dire Dawa station interface is clearly less complex and brings together less stakeholders, given its peri-urban character but also the sheer dominance of the ERC (especially at the highresolution level of analysis, see Figure 4A). The Dire Dawa city administration and other citylevel stakeholders have very little control over decisions affecting this infrastructure interface. Still, for all these infrastructural elements the ERC had to once again closely coordinate with the Prime Minister's Office and work with other federal and Chinese entities. ${ }^{5}$ The power

\footnotetext{
${ }^{5}$ MoT, MoFED, Federal Transport Authority, CREC, CCECC, and China Exim-Bank. At the medium resolution level (Figure 4B), this site also had the additional influence of stakeholders from the industry sector such as the Industrial Parks Development Commission, the Dire Dawa Industrial Zone Management, and the Metals
} 
vested to the ERC through the Prime Minister's Office also allowed this agency to handle challenges connected to private land owners and a project site that cuts across different regional authorities quite swiftly. The level of centralisation of the Dire Dawa interface is also illustrated by the presence of the Federal Police, National Intelligence, Immigration, and Customs at the station.

\subsection{The two interfaces compared}

Figure 5 illustrates the various components of the infrastructure systems (the nodes) and the interaction between them (the ties) for both case-studies. These infrastructure system illustrations were developed based on the elements discussed in the previous two sections and the direct observation of the operations at the two interfaces ${ }^{6}$. The positioning of each systems element in these illustrations does not have a direct relationship with their spatial location (although it is possible to explore these relationships by analysing Figure 5 together with Figures 3 and 4). Rather, these elements were positioned according to a qualitative assessment of their hierarchy - in terms their relevance for or association with each interface - placing more prominent elements at the centre and those with a more indirect relationship with the overall infrastructure interface at the periphery.

The schematic illustrations display the cases where the various elements are connected through active transport interfaces (type \#1 or \#2) or inter-sector interfaces (type \#3). ${ }^{7}$ The graphs in Figure 5 also cluster the various elements into eight infrastructure systems and depict the perceived strength of their interaction (the smoother and more frequent the interaction, the thicker the tie between elements; if there is no interaction, there is no tie). These clusters include two interchange systems - (1) interchange structures and (2) interchange moving parts - and two connection systems (3) horizontal and (4) vertical connections (only relevant for the case of Leghar). The other infrastructure systems identified are (5) public space, (6) utility, (7) rail energy and (8) buildings. All the evaluations and classifications represented in Figure 5 were done qualitatively by the research team based on the empirical data collected.

The different types of system components (e.g. relating to passengers and freight) and scales (catchment areas, expressed here by the density of system components) of the two interfaces are illustrated in these two visualisations. The interaction radius in Leghar is considerably smaller than in Dire Dawa (see also Figures 3 and 5). Still, despite the smaller scale, in Leghar there is a plethora of interactions with more competing interests and jurisdictional authorities. The illustrations also display the passenger transport interchange character of the LRT station as opposed to the emphasis placed on freight and industry of the Dire Dawa station. The system of infrastructure interfaces in Dire Dawa has additional interchange structures and more moving parts related to freight. In Leghar, there is also a vertical connection (sub)system whilst in Dire Dawa the interfaces only develop horizontally. As streets, instead of highways, the road infrastructure around Leghar station also has an important place function in addition to a mobility function. Similarly, the building functions in and around the Addis Ababa case-study mostly relate to people, whereas in Dire Dawa there is a prevalence of functions related to

Engineering Corporation. Other federal government players such as the Ethiopian Roads Authority, Ethiotelecom and Ethiopian Electric Power played ancillary roles at this site. The same applies to the Dire Dawa City Mayor's Office, the Dire Dawa Land Administration Bureau, the City Bus agency and the Melka Jebdu Kebele who basically followed ERC's lead.

${ }^{6}$ Site briefings were prepared with several photos at different times of the day.

7 To facilitate the reading of the maps, Figure 5 only shows one example of interfaces type \#1, \#2 and \#3 for each case-study. Please refer to Figure 1 for the different types of infrastructure interfaces. 
cargo. Generally, there is a far lower people-flow orientation in the case of Dire Dawa. Perhaps as a consequence of this, the transport infrastructure components of Dire Dawa have much smoother and more effective interfaces with the industrial infrastructure components than the ones that exist in Leghar between the LRT station and the surrounding built environment (e.g. office, residential and retail spaces).

\section{Leghar Station System}
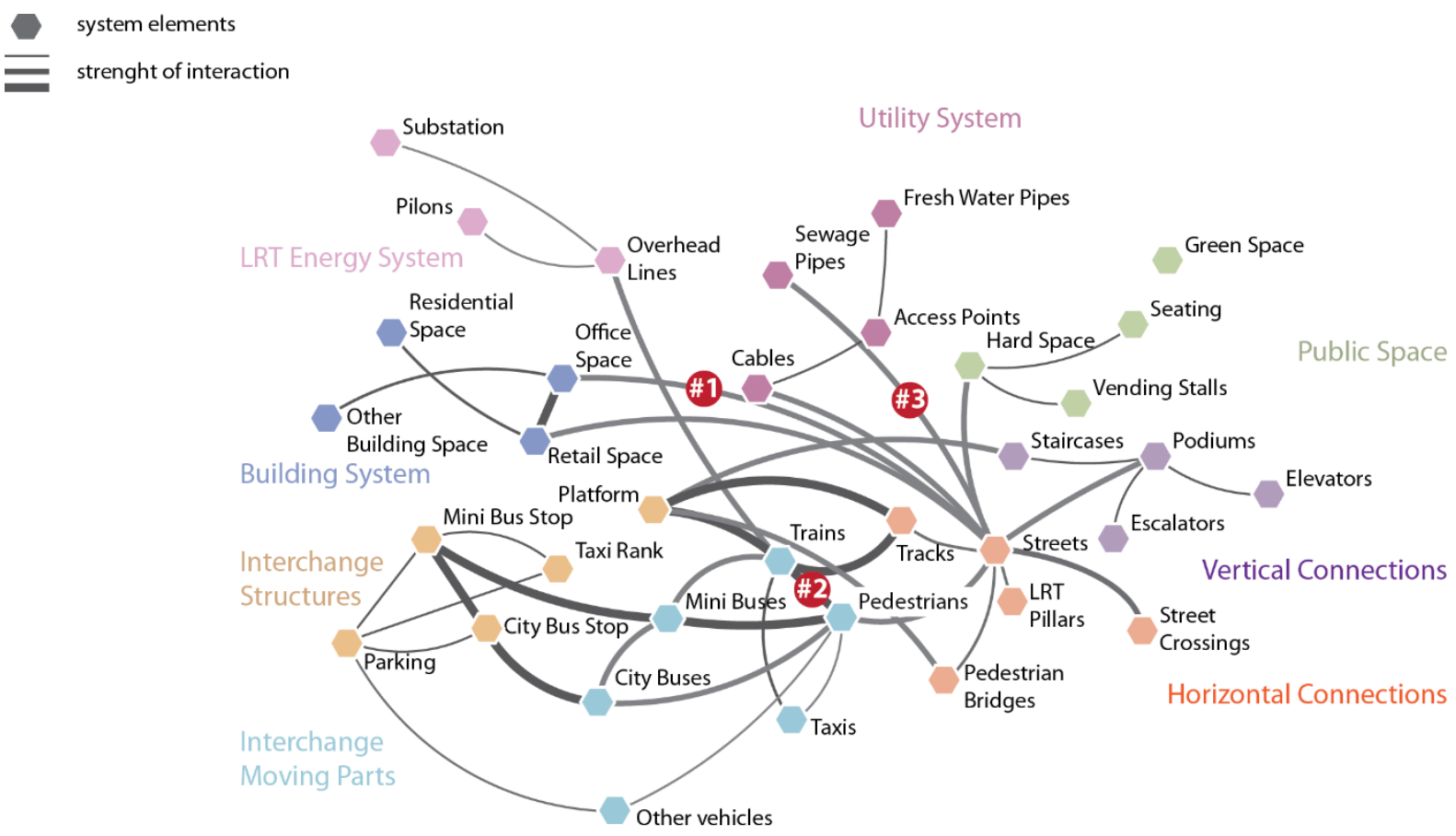

\section{Dire Dawa Station System}

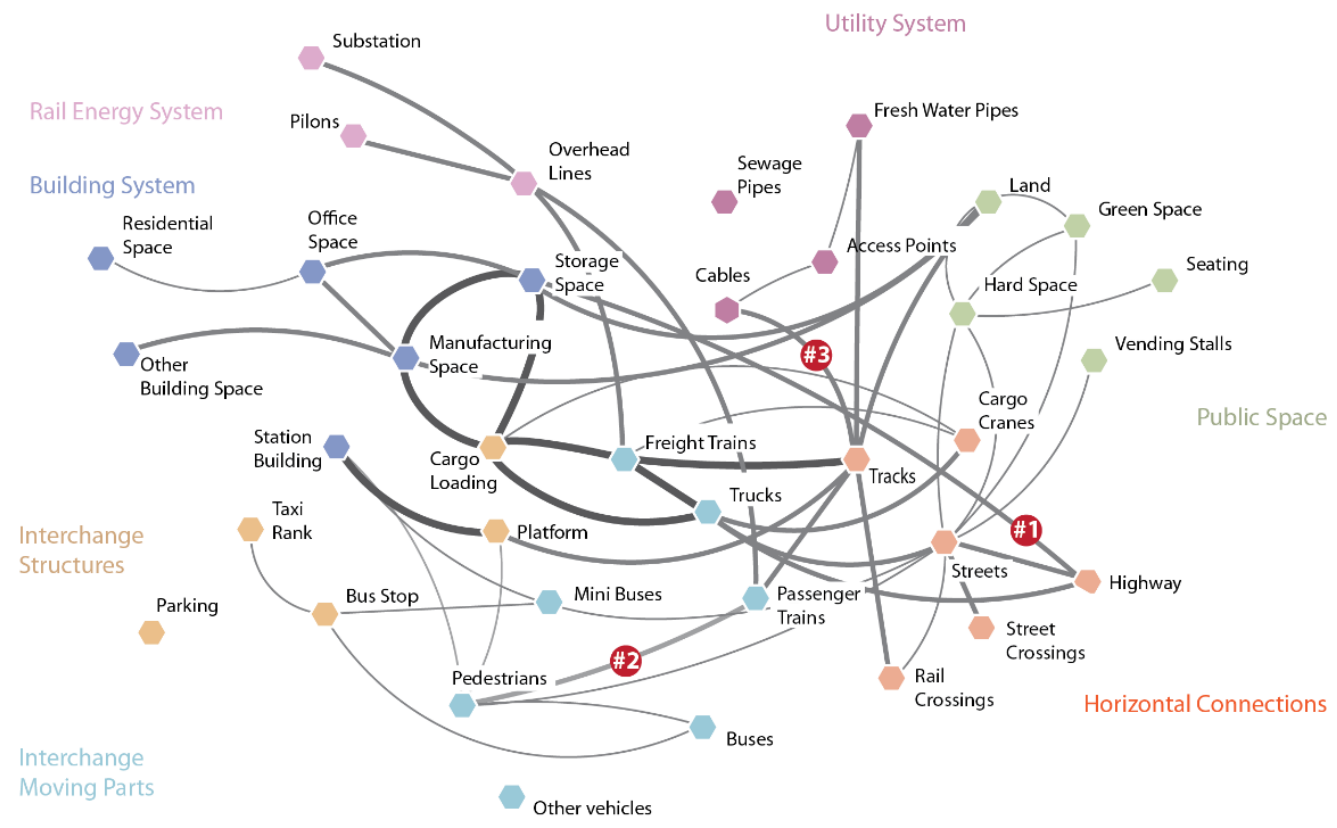

Figure 5. Schematic representations of infrastructure interfaces in Leghar and Dire Dawa

In both cases the rail energy systems and the utility systems follow similar dynamics, while in Dire Dawa there is no sewage network. Furthermore, unlike with the LRT system where the street network guides the co-location of other utility systems, in Dire Dawa it is much more the 
track that works as an infrastructure corridor. Finally, the public space elements and interfaces are also analogous across both rail stations in the way they are (not) embedded in the wider infrastructure system (the main difference lying in the fact that all these elements fall within the purview of a singular organisation in the case of Dire Dawa - the ERC).

The way the various elements are (dis)connected in Leghar indicate that the station was not regarded as an opportunity to upgrade public space. Pedestrian infrastructure, in particular, was clearly not a valued perspective but the same can be said about the road infrastructure. Overall, the frictious or inexistent interfaces between the LRT station elements and the other system elements suggests that this transport infrastructure was rigidly forced upon the place rather than developed with the place in mind.

In Dire Dawa there is less interface friction but the disconnection to the city also goes beyond the mere distance to the urban centre. Visibly, there was little consideration for placemaking and for serving the population of the city or even the small settlement of Melka Jebdu in the vicinity of the station. The bus stops, taxi ranks or parking spaces are limited and infrequently used. The connection to the old railway station in the city centre is completely non-existent. The passenger infrastructure seems to arise as an add-on to an infrastructure system which was mainly devised to move goods.

\section{Governing interfaces}

In this section, we discuss the main governance findings of our research across the two case study interfaces based on the earlier introduced framework for operationalising integrated governance by Rode (2018b). This allows us to highlight (1) the role of centralised and hierarchical coordination, and (2) limited network governance and other forms of coordination. Our empirical analysis also identifies significant differences across project phases which we discuss in the last part of this section.

In addition, Heeres' et al (2012) integration spectrum is a useful framework to differentiate the two rail projects. The LRT could be characterised as a line-oriented approach concerned mainly with rail-internal optimisation of a pre-defined right-of-way corridor. Context-sensitivity was limited to a few specific, historically and culturally sensitive sites, which is reflected more concretely at the Leghar station interface by the lack of systems integration. By contrast, the national railway system, which is part of a wider industrialisation programme, can be categorised as a case of area-oriented planning. The associated industrial and logistics developments are illustrative of this. The Dire Dawa interface which includes land developments for more than 4,200 ha also incorporates several other land functions and infrastructure systems, above all road development (see Figure 4). However, as discussed below, the project fell short of an area development process and total design as it failed to fully incorporate all interests of stakeholder within the concerned area.

\subsection{Centralised and hierarchical coordination}

Regardless of the level of integration, basic coordination was necessarily part of both analysed projects and their implementation would have been impossible without. Our fieldwork revealed that across the various integration mechanisms (see Figure 2), 'structures' based on hierarchical and central leadership prevailed. Both the ADR and Addis Ababa's LRT were projects instructed by the highest political level. The former Ethiopian Prime Minister Meles Zenawi considered these of strategic interest to Ethiopia's development and was personally dedicated to successful and rapid implementation. His interest and leadership translated to coordination 
approaches centralised at the Prime Minister's Office which were evident even at the level of each of the two analysed transport interfaces, the Dire Dawa station and the Legehar station.

The degree to which this extremely hierarchical form of coordination disrupted city-level urban governance became most evident during the design and implementation phase of the LRT project and the degree to which city-level strategic transport planning was overruled. During the early stages around 2005, not only did the city already have an elaborate Bus Rapid Transit (BRT) plan in place which included the central corridors that were later used for the LRT, but it was experimenting with priority bus lanes and had laid the asphalt for BRT introduction. A further example of tight centralised control was the confusion about the type of light rail to be built in Addis (a tram or light metro system). According to one city administration official, city-level transport professionals only became aware of the chosen type when high curbs and fences were being built indicating a light metro choice (City Transport Official C, 2018).

Having reviewed the initial report by the Technical Advisory Group (TAG) in 2005, the Prime Minister's Office commissioned the establishment of the ERC for operationalising centralised control. Its first Chief Executive, Dr. Getachew Betru, one of the members of the TAG, was handpicked by Meles Zenawi. The ERC was established to be the central node for all of Ethiopia's rail projects and to deal with inter-sectoral coordination across scales. It was formally set-up by parliament in 2007 and its CEO was reporting directly to the Prime Minister. The commandeering role of ERC as part of both projects and the analysed interfaces was acknowledged by all interviewees and according to one official, it was even able to side-line Ethiopia's Federal Ministry of Transport.

Our research also indicated important variations in ERC's levels of control linked to the differences in the nature of the two systems and their interfaces. While national rail concerns linked to the ADR were more naturally part of ERC's remit, the urban transport character of Addis' LRT made this choice less obvious. In fact, initially the LRT desk was housed within Addis Ababa's City Road Authority and only later transferred to the ERC. Attitudes towards ERC-led coordination were particularly negative in Addis Ababa across planning scales both for the passive and active interfaces of Leghar station. This was well summarised by the following Ministry of Urban Development employee: "ERC should not be managing cities, it's a railway company" (Senior Official D, 2018). This same interviewee went on to highlight a central concern about governing land versus service provision: "You need the title deed, they [ERC] only have the right for servitude".

More generally, most interviewees accepted the leading role that the ERC played in regard to Addis' LRT, but the underlying disagreement became evident in relation to its excessive powers and inability to compromise. ERC's coordinating function was also very much characterised as 'one-way traffic' by individuals within the Addis Ababa City Planning Office: "When the ERC thought they needed to consult us, we sometimes were invited" (City Planner A, 2018).

Across both interfaces, more critical interviewees emphasised how little ERC coordinated with other stakeholders, particularly at the beginning. Major interface challenges included electricity supply. The ERC's attitude of 'plug and play' failed to comprehend the broader implications of running an electrified rail system and did not communicate with Ethiopian Electric Power (EEP) in a timely manner (Senior Engineer B, 2018). In turn, and according to ERC interviewees, the organisation was surprised that even with the support of the political leadership, coordination remained difficult. Utility companies did not have the accurate and up-to-date documentation of their own assets, which posed a particular challenge in this regard (Senior Official B, 2018). Throughout the implementation phase, more network-based coordination between trusting colleagues, even between ERC staff, remained challenging as it 
was not clear "which hand was working" and they "were not fully empowered as employees" to make decisions (Senior Official B, 2018).

These hierarchical and exclusive decision-making dynamics are not just a product of a lack of resources and capacities to govern inclusively, but also a result of political dynamics. EPRDF's vanguard identity is most visible in the ruling party's adherence to 'democratic centralism': decisions are made by the party's central executive committee and subsequently communicated to the technocracy (Bach, 2011). This meant that the decision-making of railway engineers, city officials and transport planners was often limited, once rubber-stamped decisions had been passed down.

The perceived rational for this tightly controlled and centralised leadership approach according to most interviewees was twofold. First, there was a perceived and real trade-off between fast delivery and broader coordination - which also resulted in a lack of extensive consultations with projected affected populations for both rail projects and their interfaces. Second, financial constraints limited broader engagements with urban development concerns for which the professional capacity at least in Addis Ababa would have been available and considerable knowledge on the wider Leghar station context existed. The limited engagement was ultimately a conscious political choice and as the director of an international multilateral agency made clear, 'that's politics' and 'this is where it becomes messy' (Country Director, 2018).

\subsection{Limited network governance and other forms of coordination}

In addition to centralised control, committees facilitated stakeholder coordination but with mixed effectiveness, partially due to the capacity and agency of individuals and organisations. More networked governance structures, elaborate planning processes and integration instruments only played minor roles. Coordination remained mostly sectoral involving stakeholders operating at the scale of the entire line rather than place-based coordination specific to individual interfaces. In terms of integration 'processes' (see Figure 2), the main vehicle for wider stakeholder engagement was a form of 'coordination-by-committees'. The Railway Development Committee was organised via the Prime Minister's Office. It met monthly and included high-level individuals. ${ }^{8}$

Two committees were at the core of stakeholder coordination for the LRT project: a steering committee and a technical committee. The steering committee met weekly or biweekly and was chaired by the mayor. It included some federal departments but it was ultimately the mayor who had the decision-making power. The Board of Directors of the ERC also sat in the steering committee and was able to intervene. From the perspective of the City's Planning Commission, the steering committee was not a particularly strong committee and the mayor did not make any important decisions on the LRT (City Planner A, 2018).

The technical committee was chaired by the City Transport Bureau. The latter included AACRA, City Renewal Office, Ethiopian Electric Power, Ethiotelecom and Addis Ababa Water and Sewerage Authority. Essentially, all key technical stakeholders were included and it usually brought together the managers and directors of the relevant organisations. Technical coordination between ACCRA, utilities, electricity and ERC mainly concerned inter-sector

\footnotetext{
${ }^{8}$ Such as Sufian Ahmed (former Minister of Finance), Mekonnen Manyazewal (former National Planning Commissioner), Wondimu Gezahegn (Former Deputy Minister for Infrastructure, Policy Planning in the Prime Minister's Office), Workeneh Gebeyehu (Former Minister of Transport), Arkebe Oqubay (former Board Chairman of ERC), Azeb Asnake (former Director Ethiopian Electric Power) among other members from the Metals \& Engineering Corporation (METEC) and the Ministry of Defence.
} 
interface coordination regarding issues ranging from water mains, pedestrian issues (bridges and crossings), mixed-traffic, and right-of-way concerns. But it was always clear who had the power according to an observer based at Addis Ababa University: "Eventually the railway guys did what they had intended, there were some discussions, but nothing happened" (Transport Expert, 2018). The LRT project coordination also did not include dedicated sub-committees working on individual interfaces such as Leghar station.

The perspectives on the effectiveness of different committees ranged from "they do something if formed at the right time with the right people" to "just a waste of time". For the case of national rail integration, an ERC official raised the shortcomings of committees linked to responsibility and accountability. Our interviewee saw the committees as 'document producers' with little power and no longevity (Senior Official E, 2018). The committee-based coordination also meant that only the most senior individuals from the relevant stakeholder groups were speaking to each other. Given the volatility of the Ethiopian political landscape, the turnover of committee members and the associated loss of institutional memory was high. More technical staff at AACRA "had nothing to say in this" and "didn't get to do a design evaluation". This same interviewee went on to remark that "we were not consulted in the planning of the alignment. We weren't asked where our roads were" (City Transport Official D, 2018).

The image-building, symbolism and political value of the railways became most apparent during the planning phase. The former Prime Minister understood that infrastructure projects have the ability to symbolise modernity and development. ADR is thus not only illustrative of a lack of coordination across different agencies, but also of historical disintegration. As one interviewee argued: "the combination of Meles Zenawi's destructive historicism and China's need to reinvent the wheel and ignore local knowledge was the worst thing that could happen to the old railway" (Department Head A, 2018).

This 'old railway' refers to the Chemin-de-Fer Djibouto-Ethiopien built in 1902 and operated and maintained by railway engineers for the last century. Instead of retraining these workers and integrating them into the newly established ERC, Meles Zenawi decided to let the old railway organization "sink or swim" (Department Head A, 2018). ${ }^{9}$ This tabula rasa thinking in the inception phase of both projects highlights that governance arrangements for these infrastructure projects were also shaped by the ruling coalition's desire to gain legitimacy through aesthetic performance and timely delivery.

A final coordination domain which was repeatedly mentioned falls under the broader 'enabling' category (see Figure 2) and concerned leadership and technical capacities of organisations and individuals. Above all, the considerable advances in railway-related knowledge and expertise allowed for an increasingly confident rail-coordination approach led by ERC beyond relying on Chinese subcontractors: "Ten years ago, no one in the country had the capacity, even the railway corporation" (Transport Expert, 2018). Such knowledge and skills improvements were facilitated by scholarships at Chinese and Russian universities, new railway engineering degrees in Ethiopia, a newly established Railway Academy, and as a result of the day-to-day work experiences at ERC. In the context of capacity building, ERC centralisation was seen by our interviewees as a major advantage in establishing a hub that specialised in railway-related concerns.

Strong leadership capacities by Ethiopia's Prime Minister at the time as well as ERC's first CEO were equally important for enabling the centralised coordination described above.

\footnotetext{
9 The European Union had provided 55 million Euros for a rehabilitation project to be implemented by Italian company Consta JV, which EPRDF officials attempted to redirect towards the new railway.
} 
Individual career paths also mattered. The fact that the former Minister of Transport Diriba Kuma at one point became the Mayor of Addis Ababa chairing the technical committee compensated for the lack of formal coordination between the city and the ERC and allowed for some informal influence on behalf of the city administration.

A wide range of integration 'instruments' cutting across pre-assessments, evaluations, communication technology and financial mechanisms were almost entirely absent from our interviews. Even references to Ethiopia's elaborate framework of strategic planning documents, from the Planning Commission's Growth and Transformation Plan (GTP I and II) to Addis Ababa's Structure Plan were rare. For the case of Dire Dawa, and according to one of the Mayor's advisors, the fundamental logic of regional plans being developed based on national planning documents which in turn could have facilitated better systems integration for the Dire Dawa station was not followed: "policies were used as a reference points" (Senior Advisor, 2018).

\subsection{Coordination across project phases}

The centralised coordination via ERC was seen as particularly beneficial for implementing the two systems while arguably compromising place-based integration at the level of each of the interfaces. The centralisation of responsibilities under the ERC during the design and implementation period was considered as inevitable by some of our interviewees at the ERC. If implementation responsibilities for the LRT would have remained at ACCRA "it would have taken 4 years to build $2 \mathrm{~km}$ - it took us 3 years to build the rail through the arterial streets of this city" (Senior Official A, 2018). The advantages of a strongly centralised authority were seen as greatest for implementation:

"We built a railway through the biggest market (Merkato) in Africa ensuring 40 metres right of way with all the utilities. Nobody has experienced something like this with all these constraints" (Senior Official A, 2018).

The rapid implementation of both projects emerged as a key theme and rationale for the chosen coordination approach: "The government is in a hurry to give solution [...] without evaluating what went wrong" (Country Director, 2018). But there was also disagreement regarding the extent to which the ERC did everything behind closed doors. While some argued that the city administration was surprised to see certain LRT design features being implemented (and not being informed about it), others emphasised that the city had accepted the designs as outlined in the contractual agreements.

The EPC (Engineering-Procurement-Construction) contracting format that the ERC signed with the Chinese contractors exacerbated some of these tensions and rigidified the implementation process. Essentially, it meant that once the contract was signed there was little room for retrofitting and other stakeholders including the Federal Transport Authority, according to this interlocutor, had "no right to engage with the Chinese" (Senior Official H, 2018). Consultations that took place with Ethiopian Electric Power after the contract had been signed were described as courtesy meetings with little weight: "There should have been some sort of pre-EPC appraisal committee, because once you enter into contract with the Chinese, the flexibility to adapt is gone", particularly during implementation (Senior Engineer B, 2018).

By contrast, a decentralisation of responsibilities during the operations phase was seen as generally more advantageous, given that transport tariffs are set by the city government and transport service experiences are considerable with the city Transport Bureau. "ERC didn't have the operational experience", according to Senior Official A at the ERC (2018). Interviewees noted, for example, that ticket pricing is political and cannot be set by a detached 
technocracy like the ERC. A particularly important element of operational coordination concerns passenger safety and security which centrally involves the Addis Ababa Police with its permanent presence at the Leghar LRT station (as well as all other stations). The police also have their own division for railway which is embedded in the Operations Control Centre of the LRT. For the national rail, technical operation remains more centralised although in a new company, the Ethio-Djibouti Railway (EDR) which was established in April 2017. In addition, the Dire Dawa station is experiencing an increase in decentralised maintenance activities which are taken care of by local and regional units.

The bigger question as both projects moved towards day-to-day operations was about how to deal with land holdings and land development that may be able to generate the revenues to recover infrastructure and operational costs. For the Leghar LRT station this concerns the coordination of transit-oriented development (TOD) involving various land and urban development organisations alongside transport and other utilities in Addis Ababa. For the Dire Dawa station, coordination mainly concerns the new industrial and logistics developments, the developing of a new urban hub around the station and infrastructural and service links with the Dire Dawa city centre.

Ultimately, a smooth transition from implementation to operation as well as a more contextual governance of the respective interfaces was challenged by equalising the governance of an international rail system with that of an urban rail system.

\section{Conclusion}

Approaching urban governance research through an empirical lens focusing on transport infrastructure interfaces proved to be an insightful entry point to broader findings linked to multi-level urban governance, coordination approaches, and its politics. Extracting information on the design, implementation and operations phase of governing urban infrastructure based on the specificity of technical requirements as well as broader urban integration concerns at specific material infrastructure interfaces allowed for clear communication with key interviewees/stakeholders, a visual illustration of challenges and, ultimately, effective generalisation via empirical deduction.

There is widespread agreement that the fast pace of designing and building the LRT and the new national railway to Djibouti benefited from the institutional power and actions of the ERC and the federal government's political leadership. But this has come at a cost which the projects are suffering from today and which are visible in the context of the two analysed transport interfaces. Interviewees emphasised that city level agencies would have done a better job at coordinating with multiple stakeholders particularly at the hyper-local level (i.e. the interfaces). Our research indicates that city-level governance may be better suited for dealing with planning dynamics, achieving better integration and delivering more responsive transport operations perhaps at the cost of a lengthier implementation period. Essentially, the centralised, top-down coordination via the Prime Minister's Office and the ERC was a form of shielding and protecting key technical actors from wider stakeholder involvement and co-production in order to accelerate implementation.

In addition, there was a lack of capacity within the ERC to involve key stakeholders efficiently and constructively. Although stakeholder meetings were held on a regular basis, interviewees agreed that the processes of involvement may not have been as meaningful as they could and should have been. This is even more the case for coordination in Dire Dawa than in Addis Ababa. At the same time, it was in the capital city where professional conflicts between the perspectives of railway engineers and city transport and urban planners was a recurring theme 
in our interviews. It was also here where institutional reform pressures of the last decade have changed city level administration which started with the establishment of the Transport Programmes Management Office (TPMO), the Traffic Management Agency (TMA) as well as a dedicated infrastructure coordination office.

It is important to acknowledge that the rollout of major, large scale infrastructure systems in cities is an enormously challenging task in any context worldwide. The coordination and governance challenges faced by transport infrastructure interfaces such as Berlin's new international airport, London's new Crossrail line and New Delhi's BRT stations (a system now permanently closed) are prominent and recent examples of this. The fact that Ethiopia has been able to build and start operating two electrified rail systems in less than ten years needs to be recognised as an achievement. The lessons that can be learnt from both its successes and shortcomings - including those linked to the governance and coordination at critical interfaces - will offer invaluable insights as Ethiopia begins to roll-out its larger national railway network. A greater degree of place-based coordination linked to individual transport infrastructure interfaces that complements pure sectoral coordination might be one important implication moving forward.

\section{References}

AACPPO (2017). Addis Ababa City Structure Plan (2017-2027). Addis Ababa City Planning Project Office: Addis Ababa.

Agence France-Presse (2016). Next stop the Red Sea: Ethiopia opens Chinese-built railway to Djibouti. The Guardian.

African Development Bank (2016). Africa Economic Outlook report. OECD Publishing: Paris.

Agranoff, Robert and Beryl A. Radin (1991). "The Comparative Case Study Approach in Public Administration." Research in Public Administration, JAI Press Inc. 1: 203-231.

Ahram, A. and Jean-Paul Goode (2016). Researching Authoritarianism in the Discipline of Democracy. Social Science Quarterly. 97(4): 834-849.

Artioli, Francesca, Michele Acuto and Jenny Mcarthur (2017). "The water-energy-food nexus: An integration agenda and implications for urban governance." Political Geography 61: $215-223$

Ashby, Ross (1957). An introduction to cybernetics. London, Chapman and Hall.

Bach, Jean-Nicolas (2011). Abyotawi democracy: neither revolutionary nor democratic, a critical review of EPRDF's conception of revolutionary democracy in post-1991 Ethiopia. Journal of Eastern African Studies, 5(4): 641-663.

Banister, David (2005). Unsustainable Transport: City Transport In The New Century, Routledge.

Batty, Michael (2005). Cities and Complexity: Understanding Cities with Cellular Automata, Agent-based Models, and Fractals, MIT Press.

Batty, Michael (2010). Complexity in city systems: Understanding, evolution, and design. A Planner's Encounter with Complexity. E. A. S. Gert de Roo. London and New York, Routledge. 
Beall, Jo, Zegeye Cherenet, Liza Cirolia, Nuno F. da Cruz, Sue Parnell and Philipp Rode (2019). Understanding infrastructure interfaces: common ground for interdisciplinary urban research? Journal of the British Academy, 7(s2): 11-43.

Bertolini, Luca (2010). Complex systems, evolutionary planning? A Planner's Encounter with Complexity. E. A. S. Gert de Roo. London and New York, Routledge.

Bertolini, Luca (2012). "Integrating mobility and urban development agendas: a manifesto." disP-The Planning Review 48(1): 16-26.

Bogner, Alexander, Beate Littig and Wolfgang Menz (2009). Introduction: Expert Interviews - An Introduction to a New Methodological Debate. Interviewing experts. A. Bogner, B. Littig and W. Menz, Springer.

Brooker, Daniel (2012). "Build it and they will come"? A critical examination of utopian planning practices and their socio-spatial impacts in Malaysia's "intelligent city". Asian Geographer, 20(1): 39-56.

Cervero, Robert, Erick Guerra and Stefan Al (2017). Beyond Mobility: Planning Cities for People and Places, Island Press.

Cirolia, Liza and Philipp Rode (2019). 'Urban infrastructure and development.' LSE Cities Working Papers, Research Strand 03: Urban Governance and Institutional Frameworks, London.

Clapham, Christopher (2018). The Ethiopian developmental state, Third World Quarterly, 39(6): 1151-1165.

Corbin, Juliet and Anselm Strauss (2014). Basics of Qualitative Research: Techniques and Procedures for Developing Grounded Theory, SAGE Publications.

Coward, L Andrew and Nikos A. Salingaros (2004). "The information architecture of cities." Journal of Information Science 30(2): 107-118.

da Cruz, Nuno F., Philipp Rode and Michael McQuarrie (2019). New urban governance: a review of current themes and future priorities. Journal of Urban Affairs, 41(1): 1-19.

Daher, Bassel T and Rabi H. Mohtar (2015). "Water-energy-food (WEF) Nexus Tool 2.0: guiding integrative resource planning and decision-making." Water International 40(5-6): 748-771.

de Roo, Geert (2003). Environmental planning in the Netherlands: too good to be true: from command-and-control planning to shared governance, Ashgate.

de Roo, Gert (2010). "Being or becoming? That is the question! Confronting complexity with contemporary planning theory." A planner's encounter with complexity: 19-40.

DeLaurentis, Daniel (2007). Role of Humans in Complexity of a System-of-Systems, Berlin, Heidelberg, Springer Berlin Heidelberg.

Derrible, Sybil (2017). "Urban infrastructure is not a tree: Integrating and decentralizing urban infrastructure systems." Environment and Planning B: Urban Analytics and City Science 44(3): 553-569.

Dietz, Thomas, Elinor Ostrom and Paul C. Stern (2003). "The struggle to govern the commons." science 302(5652): 1907-1912.

Dupuy, Gabriel (2008). Urban Networks-Network Urbanism. Amsterdam, Techne Press. 
Duranton, Gilles and Erick Guerra (2016). Developing a Common Narrative on Urban Accessibility: An Urban Planning Perspective. Moving to Access, The Brookings Institution.

EiABC (2016). Integrated and Coordinated Physical and Transport Infrastructure Planning and Development in Addis Ababa for Safe and Efficient Mobility. Ethiopian Institute of Architecture, Building Construction and City Development, Addis Ababa.

Ethiopian Railway Corporation (ERC). (2018, October). "Operation Report and Fault Statistics.” Report. Addis Ababa, Ethiopia.

Eusgeld, Irene, Cen Nan and Sven Dietz (2011). "“System-of-systems" approach for interdependent critical infrastructures." Reliability Engineering \& System Safety 96(6): 679-686.

Flick, Uwe (2014). An Introduction to Qualitative Research, SAGE Publications.

Flyvbjerg, Bent (2006). "Five Misunderstandings About Case-Study Research." Qualitative Inquiry 12(2): 219-245.

Friend, John and Allen Hickling (2005). Planning Under Pressure: the strategic choice approach. 3rd, Elsevier.

Geerlings, Harry and Dominic Stead (2003). "The integration of land use planning, transport and environment in European policy and research." Transport Policy 10(3): 187-196.

GIZ and ICLEI (2014). Operationalizing the Urban Nexus: Towards resource-efficient and integrated cities and metropolitan regions. GIZ Eschborn.

Glaeser, Edward L. (2008). Cities, agglomeration, and spatial equilibrium, Oxford University Press.

Golubski, Christina (2017). Chinese-financed Ethiopia-Djibouti railway is completed. Africa in Focus, Brookings: Washington, DC. Accessed on 24 May 2019: https://www.brookings.edu/blog/africa-in-focus/2017/01/27/africa-in-the-news-ethiopiadijbouti-railway-complete-au-summit-held-and-the-gambia-crisis-ends/

Goodwin, Phil, Sharon Hallett, Francesca Kenny and Gordon Stokes (1991). Transport, the new realism, Transport Studies Unit, Oxford University.

Government of Ethiopia (2010). Second Growth and Transformation Plan (GTP) (2010/112014/15).

Graham, Stephen (2009). "Networked infrastructure and the urban condition." Open City: Designing Coexistence edited by Tim Rieniets and Jennifer Sigler: 416.

Graham, Stephen and Simon Marvin (2001). Splintering urbanism: networked infrastructures, technological mobilities and the urban condition, Routledge.

Hajer, Maarten A. (1995). The politics of environmental discourse: ecological modernization and the policy process. Wotton-under-edge, UK, Clarendon Press.

Heeres, Niels, Taede Tillema and Jos Arts (2012). "Integration in Dutch planning of motorways: From "line" towards "area-oriented" approaches." Transport Policy 24: 148158.

Heeres, Niels, Taede Tillema and Jos Arts (2016). "Dealing with interrelatedness and fragmentation in road infrastructure planning: an analysis of integrated approaches throughout the planning process in the Netherlands." Planning Theory \& Practice 17(3): 421-443. 
Hickman, Robin, Moshe Givoni, David Bonilla and David Banister (2015). Handbook on Transport and Development, Edward Elgar Publishing.

Holland, John H. (2000). Emergence: From chaos to order, OUP Oxford.

Jamshidi, Mo (2008). Systems of systems engineering: principles and applications, CRC press.

Jessop, Bob (2003). "Governance and meta-governance: on reflexivity, requisite variety and requisite irony." Governance as social and political communication: 101-116.

Kassahun, Meseret and Sebawit Bishu (2015). "The Governance of Addis Ababa Turn Around Projects: Addis Ababa Light Rail Transit and Housing." Partnership for African Social and Governance Research.

Kennedy, Christopher, Eric Miller, Amer Shalaby, Heather MacLean and Jesse Coleman (2005). "The Four Pillars of Sustainable Urban Transportation." Transport Reviews 25(4): 393-414.

Kessel, Clive (2012). Ingenuity at the interface. Rail Engineer. Accessed on 16 May 2019: https://www.railengineer.co.uk/2012/03/14/ingenuity-at-the-interface

Krugman, Paul (1991). "Increasing Returns and Economic Geography." Journal of Political Economy 99(3): 483-499.

Lefort, René (2013). The theory and practice of Meles Zenawi: A response to Alex de Waal. African Affairs. 112(448): 460-470.

Lempert, Robert J, Steven W Popper and Steven C Bankes (2003). "Shaping the next one hundred years: new methods for quantitative." Long-term policy analysis 208.

Littig, Beate and Franz Pöchhacker (2014). "Socio-Translational Collaboration in Qualitative Inquiry: The Case of Expert Interviews." Qualitative Inquiry 20(9): 1085-1095.

Lu, Yi and Bin Chen (2016). "Energy-water nexus in urban industrial system." Energy Procedia 88: 212-217.

Macário, Rosario (2014). Access as a social good and as an economic good: is there a need for a paradigm shift? Urban Access for the 21st Century, Routledge: 101-131.

Mitleton-Kelly, E. (2015). 'Urban governance: A complexity theory approach.' New urban governance foresight seminar series. LSE Cities: London.

Nallet, Clélie (2018). 'The Challenge of Urban Mobility: A Case Study of Addis Ababa Light Rail, Ethiopia.' Notes de l'Ifri, Ifri.

National Planning Commission (2016). Growth and Transformation Plan II (2015/162019/20). Addis Ababa, Ethiopia: Government of Federal Democratic Republic of Ethiopia.

New Climate Economy (2015). Unlocking the Power of Ethiopia's Cities. Global Commission on the Economy and Climate: London and Washington, DC.

Newlove-Eriksson, Lindy (2019). Accountability and Patchwork Governance in Urban Rail Interchanges: Junctions of London Crossrail and Stockholm City Line Compared. Public Works Management \& Policy, in press. DOI: 10.1177/1087724X19866461

Pfadenhauer, Michaela (2009). At Eye Level: The Expert Interview - a Talk between Expert and Quasi-expert. Interviewing experts. A. Bogner, B. Littig and W. Menz, Springer. 
Phelan, Steven E. (1999). "A Note on the Correspondence Between Complexity and Systems Theory." Systemic Practice and Action Research 12(3): 237-246.

Richards, Sue (1999). Cross-cutting issues in public policy and public service : report of a research project for DETR by the School of Public Policy, University of Birmingham. London, Department of the Environment, Transport and the Regions.

Rittel, Horst W. J. and Melvin M. Webber (1973). "Dilemmas in a general theory of planning." Policy Sciences 4(2): 155-169.

Rode, Philipp (2018a). Ethiopia's Railway Revolution. Urban Age Developing Urban Futures. London, LSE Cities.

Rode, Philipp (2018b). Governing Compact Cities: How to connect planning, design and transport, Edward Elgar.

Rode, P., Catarina Heeckt and Nuno F. da Cruz (2019). National transport policy and cities: key policy interventions to drive compact and connected urban growth. Coalition for Urban Transitions: London and Washington, DC.

Rode, Philipp, Graham Floater, Nikolas Thomopoulos, James Docherty, Peter Schwinger, Anjali Mahendra and Wanli Fang (2017). Accessibility in Cities: Transport and Urban Form. Disrupting Mobility: Impacts of Sharing Economy and Innovative Transportation on Cities. G. Meyer and S. Shaheen. Cham, Springer International Publishing: 239-273.

Rydin, Yvonne (2011). The Purpose of Planning: Creating Sustainable Towns and Cities. Bristol, UK, Policy Press.

Slater, Sandy, Oksana Pugach, Wanting Lin and Anita Bontu (2016). If you build it will they come? Does involving community groups in playground renovations affect park utilization and physical activity? Environment and Behavior, 48(1): 246-265.

Terrefe, Biruk (2018). The 'Renaissance' Railway: Infrastructure and Discourse in EPRDF's Ethiopia. MPhil thesis, Oxford Department of International Development, Oxford University: Oxford.

UN (2016). New Urban Agenda.

UN Habitat (2009). Planning Sustainable Cities - Global Report on Human Settlements 2009. Nairobi.

UNEP (2011). Towards a Green Economy: Pathways to Sustainable Development and Poverty Eradication. New York, NY, UNEP.

Walker, R Villarroel, M Bruce Beck, Jim W Hall, Richard J Dawson and Oliver Heidrich (2014). "The energy-water-food nexus: Strategic analysis of technologies for transforming the urban metabolism." Journal of environmental management 141: 104-115.

World Bank (2016). Ethiopia Public Expenditure Review. World Bank Group: Washington, DC.

Yin, Robert K. (2013). Case Study Research: Design and Methods, SAGE Publications.

\section{$\underline{\text { Referenced Interviews: }}$}

City Planner (A). (2018, October $5^{\text {th }}$ ). Addis Ababa, Ethiopia: Addis Ababa City Planning Commission. Personal Interview. 
City Transport Official (C). (2018, November 22 $\left.{ }^{\text {nd }}\right)$. Addis Ababa, Ethiopia: Transport Programmes Management Office. Personal Interview.

City Transport Official (D). (2018, December $7^{\text {th }}$ ). Addis Ababa, Ethiopia: Addis Ababa City Roads Authority. Personal Interview.

Country Director. (2018, November $\left.26^{\text {th }}\right)$. Addis Ababa, Ethiopia: International Multilateral Agency. Personal Interview.

Department Head (A). (2018, November 12 ${ }^{\text {th }}$. Addis Ababa, Ethiopia: Chemin-de-Fer EthioDjiboutien. Personal Interview

Senior Advisor. (2018, November 1 ${ }^{\text {st }}$ ). Dire Dawa, Ethiopia: Dire Dawa Mayor's Office. Personal Interview.

Senior Engineer (B). (2018, November 22 $\left.{ }^{\text {nd }}\right)$. Addis Ababa, Ethiopia: Ethiopian Electric Power. Personal Interview.

Senior Official (A). (2018, October $\left.4^{\text {th }}\right)$. Addis Ababa, Ethiopia: Ethiopian Railway Corporation. Personal Interview.

Senior Official (B). (2018, October $\left.4^{\text {th }}\right)$. Addis Ababa, Ethiopia: Ethiopian Railway Corporation. Personal Interview.

Senior Official (C). (2018, October $5^{\text {th }}$ ). Addis Ababa, Ethiopia: Ethiopian Railway Corporation. Personal Interview.

Senior Official (D). (2018, October 18 $\left.{ }^{\text {th }}\right)$. Addis Ababa, Ethiopia: Ministry of Urban Development. Personal Interview.

Senior Official (E). (2018, October 25 $\left.5^{\text {th }}\right)$. Addis Ababa, Ethiopia: Ethiopian Railway Corporation. Personal Interview.

Senior Official (H). (2018, November $\left.2^{\text {nd }}\right)$. Dire Dawa, Ethiopia: Federal Transport Authority. Personal Interview.

Ticket Seller. (2019, January $\left.13^{\text {th }}\right)$. Addis Ababa, Ethiopia: Ethiopian Railway Corporation. Personal Interview.

Transport Expert. (2019, November 27 $7^{\text {th }}$. Addis Ababa, Ethiopia: Addis Ababa University. Personal Interview. 


\section{Appendix 1}

Timeline of Ethiopia's railways projects.

Ethiopian Government Milestones

General Ethiopian Railway Corporation Milestones

Specific Light-Rail-Transit (LRT)

Milestones

Specific Addis-Djibouti Railway (ADR

Highly contested

2005 elections

PM announces

"Grand Ethiopian

Renaissance Dam"

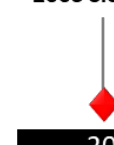

\begin{tabular}{l|l|l}
2005 & 2006 & 2007
\end{tabular}

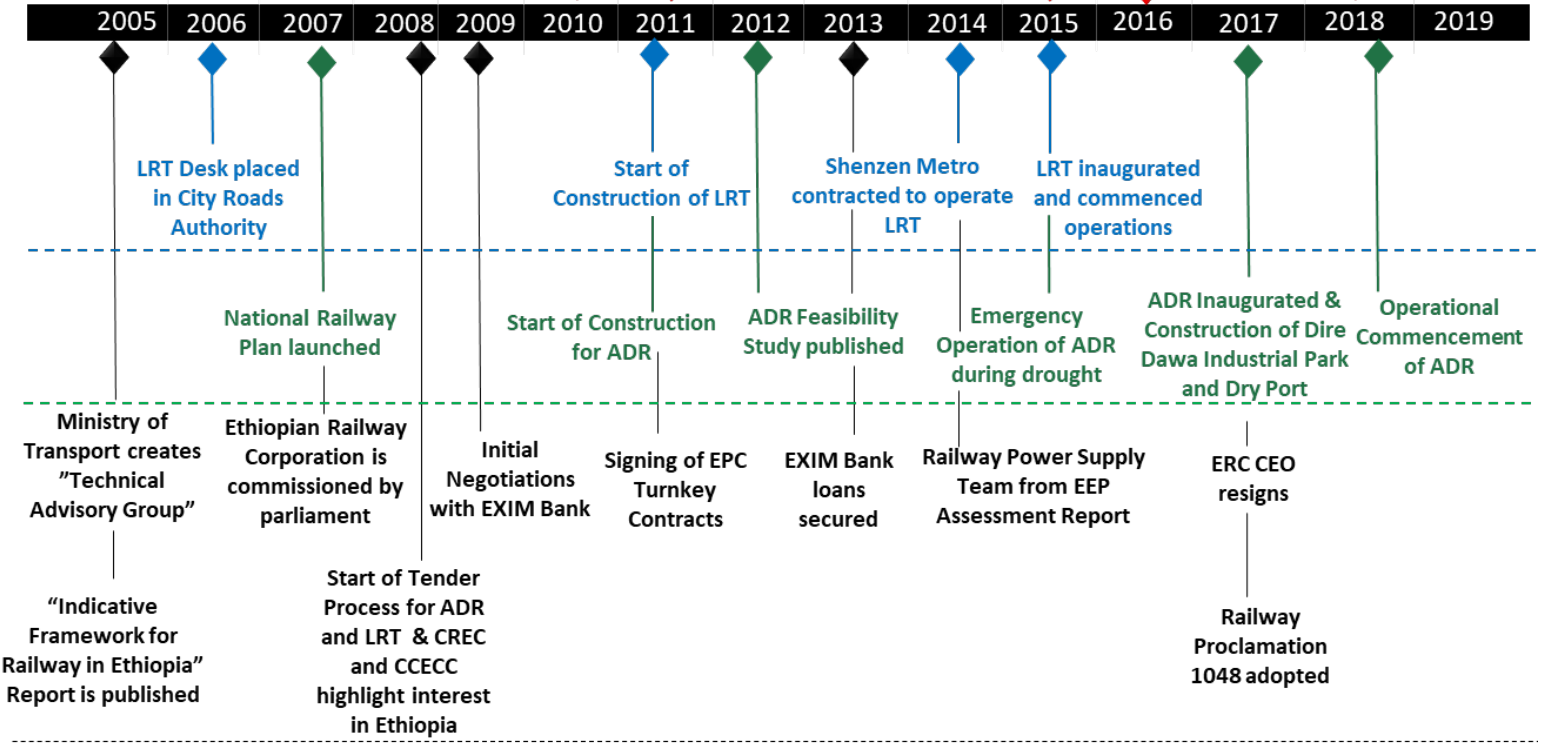

thiopia launches

Growth and

Transformation

Plan (GTP) I

(2010-2015)

Former PM Meles

Zenawi passes away

and is replaced by

PM Hailemariam

Desalegn

2010 elections

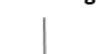
named PM by party Ethiopia launches April Transformation Plan (GTP) II

EPRDF wins (2016-2020) PM Hailemariam elections by $100 \%$

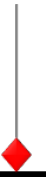

Desalegn resigns

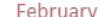




\section{Appendix 2}

Key stakeholders and their involvement across the various phases of the project.

Stakeholders at the Addis Ababa Interface (across project phases of the Addis Ababa LRT)

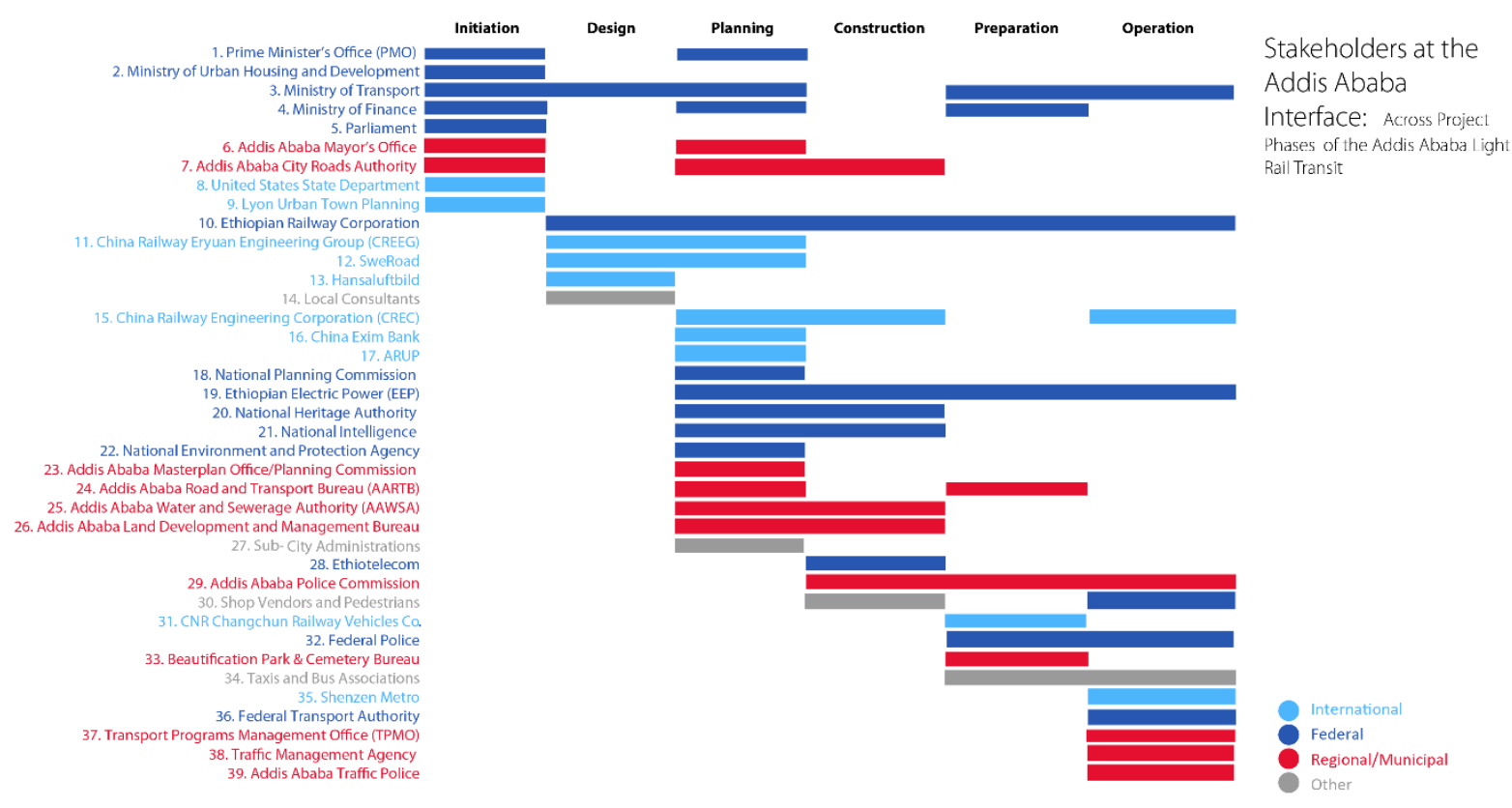

Stakeholders at the Dire Dawa Interface (across project phases of the Addis-Djibouti Railway)

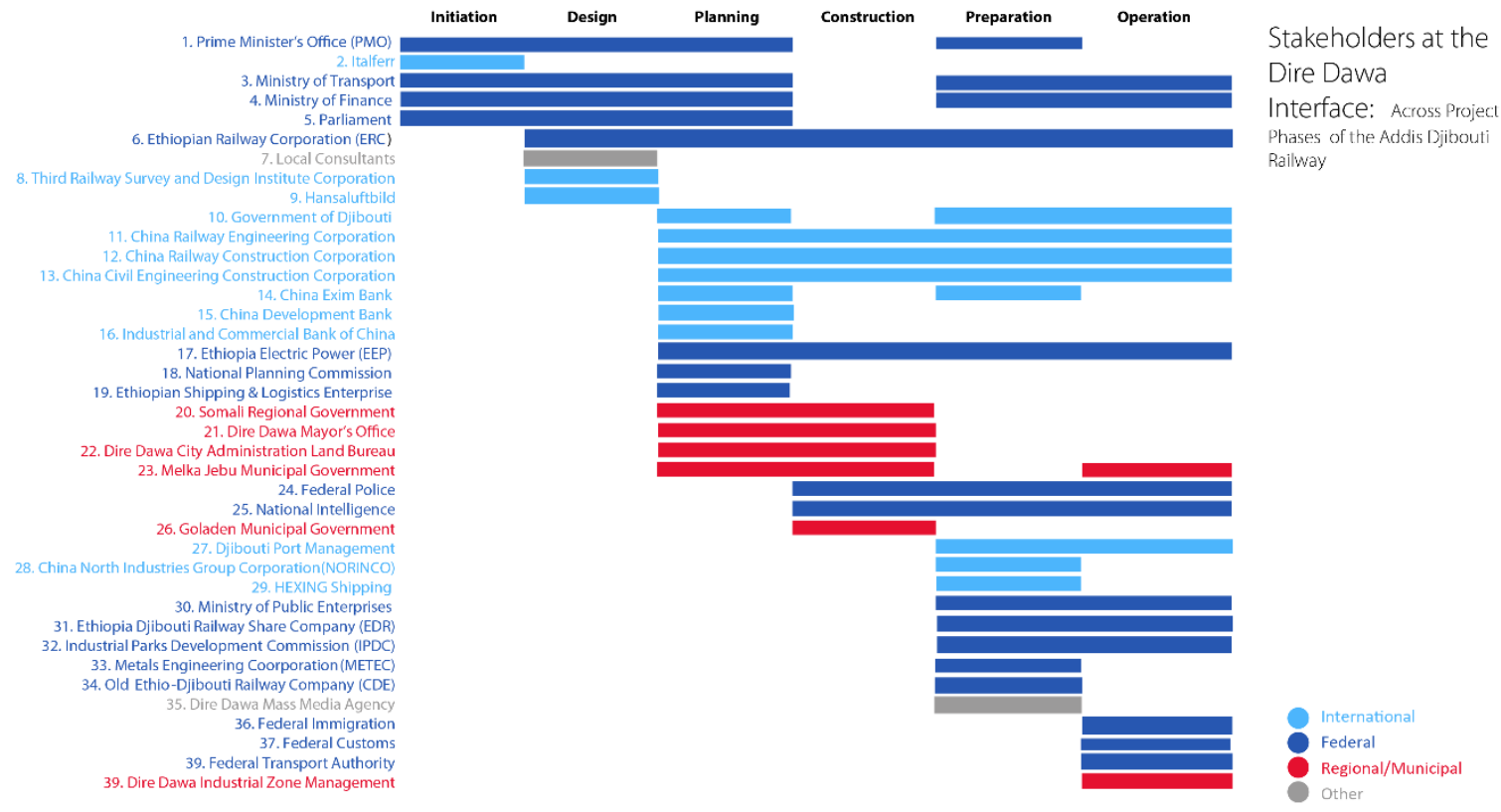




\section{Appendix 3}

Standard interview script and complete interview list organised by date (referenced interviews are mentioned above).

As explained in the methods section, the interviews were semi-structured and specific questions were added/removed/adapted ahead of the meeting depending on the profile of the interviewee or during the meeting to react more organically to his/her responses. The questions listed below were asked in the vast majority of the interviews to connect this data collection device to our theoretical framework.

1. Professional background/discipline and key stages of professional employment.

2. What have been the biggest governance challenges for introducing the Addis-Djibouti Railway/LRT in Addis Ababa? What were the most prominent administrative and institutional challenges?

3. Who were the key actors developing the railway? What were the initial negotiations like and how did those change?

4. What were the toughest contractual negotiations? What were the easiest negotiations?

5. What were the big governance trade-offs such speed of delivery/inclusive consultation?

6. How much did you have to think about system integration within very specific locations (e.g. stations) vs linear infrastructure issues at the macro level?

7. What is the biggest difference in terms of stakeholders and design and implementation challenges when you move from the Addis Djibouti Railway / Addis LRT system to the stakeholders engaged and challenges involved with the Dire Dawa / Leghar station in particular? What does this imply for the governance challenges? Who becomes more pronounced at the station level?

8. At what scale was the requirement for coordination with other stakeholders and actors most pronounced in and around Dire Dawa station / Leghar station? (Macro/Meso/Micro)

9. How has the involvement of key actors changed over time and for different phases of the infrastructure life-cycle (idea, concept, feasibility, planning, financing, project, construction, operation, maintenance, recommissioning/ refurbishment/upgrade)?

10. Dry Port and Industrial Park in Dire Dawa: how connected are these to the railway station? What technical details had to be resolved? / Why was the LRT ultimately favoured as opposed to the BRT (Bus Rapid Transport), which was a clear option at the time? How different would the stop/station in Leghar be?

11. Station Locations: (Dire Dawa built around old railway, Melka Jebdu quite far out, many residents have little access, what was the rationale here?) / (Leghar station and related traffic disruption in two key arteries of Addis Ababa, what was the rationale here?)

12. Vertical integration: To which extent did the coordination of urban and transport planning between Dire Dawa / Addis Ababa, National Government and ERC change?

13. Horizontal integration: To which extent has the integration between urban planning and transport changed?

14. What was the particular advantage and disadvantage of centralising all rail developments at ERC?

15. Which elements of railway governance in Ethiopia exemplify joined-up governance and institutional arrangements? In contrast, which elements are the most fragmented in terms of governance and lack essential integration? 


\begin{tabular}{|c|c|c|c|c|}
\hline \# & Date & Location & Title (code) & Institution/affiliation \\
\hline 1 & 03.10 .2018 & Addis Ababa & City Transport Official (A) & $\begin{array}{l}\text { Transport Programmes Management } \\
\text { Office }\end{array}$ \\
\hline 2 & 04.10 .2018 & Addis Ababa & Senior Official (A) & Ethiopian Railway Corporation \\
\hline 3 & 04.10 .2018 & Addis Ababa & Senior Official (B) & Ethiopian Railway Corporation \\
\hline 4 & 05.10 .2018 & Addis Ababa & City Planner (A) & $\begin{array}{l}\text { Addis Ababa City Planning } \\
\text { Commission }\end{array}$ \\
\hline 5 & 05.10 .2018 & Addis Ababa & Senior Official (C) & Ethiopian Railway Corporation \\
\hline 6 & 05.10 .2018 & Addis Ababa & Researcher & $\begin{array}{l}\text { Ethiopian Development Research } \\
\text { Institute }\end{array}$ \\
\hline 7 & 07.10 .2018 & Addis Ababa & Lead Architect & Architecture Agency in Addis Ababa \\
\hline 8 & 08.10 .2018 & Addis Ababa & $\begin{array}{l}\text { Transport Planning Consultant } \\
\text { (A) }\end{array}$ & International NGO (\#1) \\
\hline 9 & 08.10 .2018 & Addis Ababa & $\begin{array}{l}\text { Transport Planning Consultant } \\
\text { (B) }\end{array}$ & International NGO (\#2) \\
\hline 10 & 18.10 .2018 & Addis Ababa & Senior Official (D) & Ministry of Urban Development \\
\hline 11 & 25.10 .2018 & Addis Ababa & Senior Official (E) & Ethiopian Railway Corporation \\
\hline 12 & 30.10 .2018 & Dire Dawa & Senior Official (F) & $\begin{array}{l}\text { Ethio-Djibouti Railway Share } \\
\text { Company }\end{array}$ \\
\hline 13 & 30.10 .2018 & Dire Dawa & Security Officer (A) & $\begin{array}{l}\text { Ethio-Djibouti Railway Share } \\
\text { Company }\end{array}$ \\
\hline 14 & 31.10 .2018 & Dire Dawa & City Transport Official (B) & Dire Dawa City Administration \\
\hline 15 & 31.10 .2018 & Dire Dawa & City Planner (B) & Dire Dawa City Administration \\
\hline 16 & 01.11 .2018 & Dire Dawa & Senior Advisor & Dire Dawa Mayor's Office \\
\hline 17 & 01.11 .2018 & Dire Dawa & Senior Official $(G)$ & Federal Transport Authority \\
\hline 18 & 01.11 .2018 & Dire Dawa & Senior Engineer $(\mathrm{A})$ & Water Supply \& Sewerage Authority \\
\hline 19 & 02.11 .2018 & Dire Dawa & Senior Official $(\mathrm{H})$ & Federal Transport Authority \\
\hline 20 & 12.11 .2018 & Addis Ababa & Department Head (A) & Chemin de Fer Ethio-Djiboutien \\
\hline 21 & 22.11 .2018 & Addis Ababa & City Transport Official (C) & $\begin{array}{l}\text { Transport Programmes Management } \\
\text { Office }\end{array}$ \\
\hline 22 & 22.11 .2018 & Addis Ababa & Senior Engineer (B) & Ethiopian Electric Power \\
\hline 23 & 26.11 .2018 & Addis Ababa & Country Director & International Multilateral Agency \\
\hline 24 & 27.11 .2018 & Addis Ababa & Transport Expert & Addis Ababa University \\
\hline 25 & 27.11 .2018 & Addis Ababa & Department Head (B) & Chemin de Fer Ethio-Djiboutien \\
\hline 26 & 07.12 .2018 & Addis Ababa & City Transport Official (D) & Addis Ababa City Roads Authority \\
\hline 27 & 10.12 .2018 & Addis Ababa & Manager & Ethiopian Railway Corporation \\
\hline 28 & 19.12 .2018 & Addis Ababa & Waiter & Coffee Shop close to Leghar Station \\
\hline 29 & 19.12 .2018 & Addis Ababa & Bartender & Buffet de La Gare \\
\hline 30 & 19.12.2018 & Addis Ababa & Shoe Vendor & Leghar Intersection \\
\hline 31 & 12.01 .2019 & Addis Ababa & Minibus Driver & Leghar Intersection \\
\hline 32 & 12.01 .2019 & Addis Ababa & Station Manager & Anbassa Bus Company \\
\hline 33 & 12.01.2019 & Addis Ababa & Security Guard & Old Leghar Station \\
\hline 34 & 13.01.2019 & Addis Ababa & Shop Manager & Shebelle Suits \\
\hline 35 & 13.01 .2019 & Addis Ababa & Coffee Shop Owner & Close to Leghar Station \\
\hline 36 & 13.01 .2019 & Addis Ababa & Ticket Seller & Ethiopian Railway Corporation \\
\hline 37 & 13.01 .2019 & Addis Ababa & Security Guard & Ethiotelecom Office \\
\hline 38 & 16.01 .2019 & Addis Ababa & Book Seller & Book Shop close to Leghar \\
\hline 39 & 16.01 .2019 & Addis Ababa & Police Officer & Leghar Station \\
\hline 40 & 17.01.2019 & Addis Ababa & Senior Official (I) & $\begin{array}{l}\text { Ethio-Djibouti Railway Share } \\
\text { Company }\end{array}$ \\
\hline 41 & 18.01.2019 & Addis Ababa & Department Head (C) & Ministry of Transport \\
\hline 42 & 20.01.2019 & Addis Ababa & Teenager & Resident of Kirkos \\
\hline 43 & 20.01 .2019 & Addis Ababa & Elderly woman & Resident of Kirkos \\
\hline 44 & 21.01 .2019 & Addis Ababa & Daily commuter & Resident of Ayat \\
\hline 45 & 24.01 .2019 & Addis Ababa & Employee & Dire Dawa Mayor's Office \\
\hline 46 & 28.01 .2019 & Addis Ababa & Senior Official $(\mathrm{J})$ & Federal Transport Authority \\
\hline
\end{tabular}

